\title{
LA-8851-MS
}

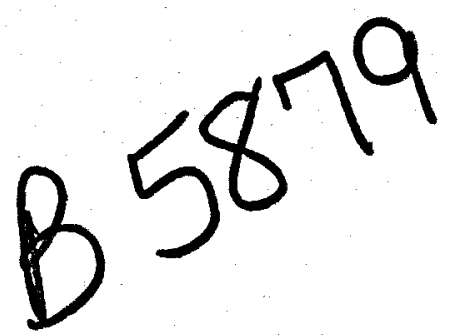

\section{Chemical-Equilibrium Calculations for Aqueous Geothermal Brines}


An Affirmative Action/Equal Opportunity Employer

Edited by Eleanor E. Langley, Group WX 4

This work was supported by the US Department of Energy, Division of Geothermal Energy.

DISCLAIMIIR

This report was propared as an actuunt of work prensored by an agency of the United States (iovern-

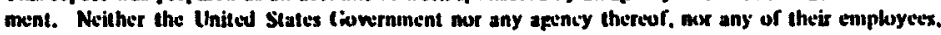
moles any warranty, exprexs or implied, or assumes any keal tiubility ur rexponsibility for the accuracy. compketemess, of uscifulness of any information. apparatux. product, or process disclosed, or reprezints that its use wuld nut infringe privelely owned rithts. Reference herein to any apecific commercial product. process, or mervice by tredte name. trademask, manufacturer, of utherwise. docs nut necessurity constitute or imply its endorsement, necummendation. or favoring by the lasited states Comernment of any azency thereor. The views and opinions of authors exprexed berein do not netcescarly stute or reflect thuse of the llnited States (iovernment or any apency thercor. 


\section{LA-8851-MS}

UC-66b

Issued: May 1981

\section{Chemical-Equilibrium Calculations for Aqueous Geothermal Brines}
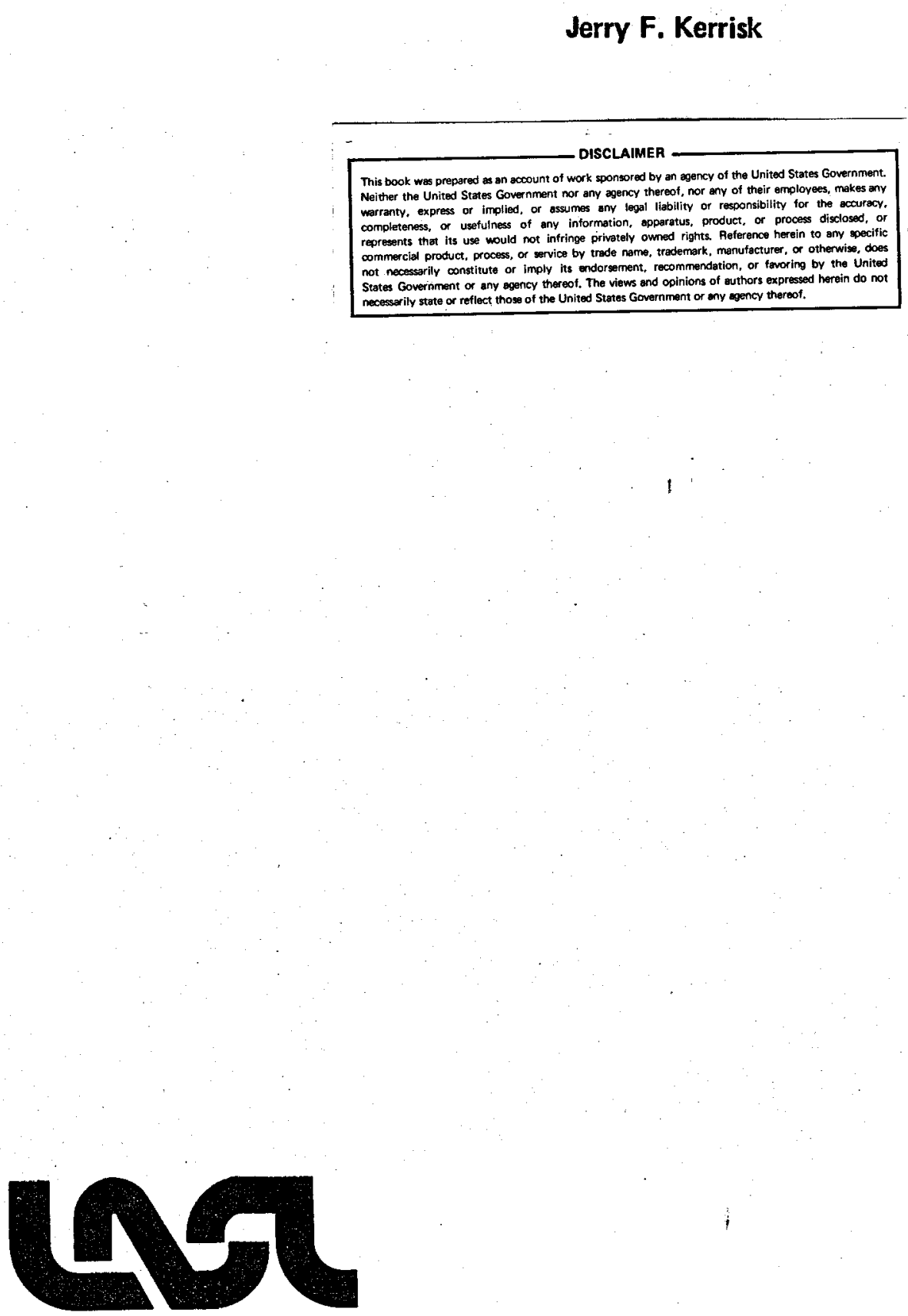
: $\therefore$

$\therefore$ 
CHEMICAL EQUILIBRIUM CALCULATIONS FOR AQUEOUS GEOTHERMAL BRINES

by

Jerry F. Kerrisk

\section{ABSTRACT :}

Results from four chemical-equilibrium computer programs, REDEQL.EPAK, GEOCHEM, WATEQF, and SENECA2, have been compared with experimental solubility data for some simple systems of interest with geothermal brines. Seven test cases involving solubilities of $\mathrm{CaCO}_{3}$, amorphous $\mathrm{SiO}_{2}, \mathrm{CaSO}_{4}$, and $\mathrm{BaSO}_{4}$ at various temperatures from 25 to $300^{\circ} \mathrm{C}$ and in $\mathrm{NaCl}$ or $\mathrm{HCl}^{4}$ solutions of $0-4$ molal have been examined. Significant differences between calculated results and experimental data occurred in some cases. These differences were traced to inaccuracies in free-energy or equilibriumconstant data and in activity coefficients used by the programs. Although currently available chemical-equilibrium programs can give reasonable results for these calculations, considerable care must be taken in the selection of free-energy data and methods of calculating activity coefficients.

\section{I. : INTRODUCTION}

Many of the recent attempts to develop geothermal technology by using geothermal brines have encountered severe problems. 1 Much of the difficulty can be traced to the chemistry of brines and involves precipitation and deposition of scale in production wells, in plant equipment or in reinjection wells, and corrosion of equipment. A complicating feature of these problems is that the chemistry of geothermal brines is highly dependent on the source of the brine, differing from field to field and even among wells in a given field. Thus, problems with one brine (along with solutions to these problems) may not be relevant to other brines.

A fundamental understanding of the chemistry of geothermal brines will be necessary to economically use these energy sources. A worthwhile goal would be the capability of modeling precipitation and corrosion reactions under conditions of varying temperature and pressure. Modeling of these processes must start with an understanding of equilibrium chemical behavior of brines (for example, with a knowledge of what species are actually present in brine and under what conditions precipitation or corrosion reactions can occur). Following this, kinetics of precipitation or corrosion reactions, diffusion of the species concerned, and physical or chemical processes involved in the deposition of scale must also be understood and modeled.

Modeling equilibrium chemical behavior of geothermal brines is conceptually a simple problem, given the thermodynamic basis of chemical-equilibrium calculations and the wide range of applications. 2 In practice, however, a number of difficulties complicate the calculations. One of the most important difficulties involves availability of free-energy or equilibrium-constant data for the chemical reactions involved. Often only roomtemperature data are known; and only rarely are high-pressure data avallable. Methods of estimating this information can be used, but they generally lack the accuracy needed. A second and equally important difficulty is the need for a method of calculating activity coefficients of species in brine at the high ionic strengths encountered. Conventional methods of calculating 
activity coefficients are limited to ionic strengths of $0-1 \mathrm{molal}$, giving only rough estimates above that range. ${ }^{3}$ Effects of temperature and pressure on activity coefficients are also important. A third difficulty involves the method employed to calculate the equilibrium composition of a brine. A method is needed that is efficient, insensitive to the initial estimate of composition, and capable of selecting which solids will precipitate from a multitude of potential precipitates. No single method available seems to possess all these attributes. 2

In the face of these difficulties, it is uncertain how well currently available chemicalequilibrium computer programs can model geothermal brines. To help answer this question, this report describes a comparison of results from four chemical-equilibrium computer programs with experimental solubility data for some simple systems of interest with geothermal brines. The four programs tested were REDEQL.EPAK, ${ }^{4}$ GEOCHEM, ${ }^{5}$ WATEQF, 6 and SENECA2.1,7 The systems employed involve the solubility of $\mathrm{CaCO}_{3}$, amorphous silica, $\mathrm{CaSO}_{4}$, and $\mathrm{BaSO}_{4}$ at various temperatures in $\mathrm{NaCl}$ or $\mathrm{HCl}$ solutions of $0-4$ molal. These comparisons test the free-energy or equilibrium-constant data available with each program and the methods employed for activity-coefficient calculations. The sources of differences between calculated results and experimental data are discussed. Finally, some more complex problems were employed to obtain timing data for three of the codes.

Calculations in high ionic strength solutions ( $>1$ molal) are certainly outside the range of applicability of these programs. This work was undertaken, however, to test the utility of various programs. Calculations outside the accepted range of applicability are a necessary part of the test.

\section{CHEMICAL-EQUILIBRIUM COMPUTER PROGRAMS}

Four chemical-equilibrium computer programs were employed in this test. They are REDEQL.EPAK, GEOCHEM, WATEQF, and SENECA2. These programs were chosen because they all contain thermodynamic data bases (free-energy or equilibrium-constant data) and they all calculate activity coefficients for species involved. The following sections briefly describe some features of each program, such as the method of calculating equilibrium compositions, the range of applicability (temperature, species, etc.), and the activity-coefficient calculations.

A. REDEQL.EPAK

REDEQL.EPAK is a modification of REDEQL2 made at the Corvallis Environmental Research Laboratory of the US Environmental Protection Agency. ${ }^{4}$ The program computes equilibrium compositions in aqueous systems; complex formation, precipitation of solids, oxidation-reduction reactions, and the presence of a gas phase are all considered. The set of mass-balance and mass-action equations is solved by iteration using the Newton-Raphson technique for a given group of possible solid phases in equilibrium with the aqueous phase. ${ }^{2}$ This operation is repeated with different groups of solid phases until the correct solid phases are found. The correct set is defined as a set for which no solubility products are exceeded and the mass-balance conditions are satisfied. Thermodynamic data for complexes and solids of 35 metals and 59 ligands are available for $25^{\circ} \mathrm{C}$ with the version employed for these tests. Although the program can adjust equilibrium constants for temperatures other than $25^{\circ} \mathrm{C}$, data needed for this adjustment (enthalpy change of the formation reaction at $25^{\circ} \mathrm{C}$ ) are available for only a small percentage of complexes or solids. Activity coefficients for charged species are calculated with the Davies equation 8

$$
-\log _{10} \gamma(Z)=A Z^{2}\left[\frac{(I)^{1 / 2}}{1+(I)^{1 / 2}}-0.2 I\right],
$$

where $\gamma$ is the activity coefficient of a species with charge $Z$ in a solution of ionic strength I molar. The parameter $A$ is calculated as a function of temperature. 4 Activity coefficients for $\mathrm{H}^{+}$are taken as $1 / 2 \log _{10} \gamma(Z=1)$. Uncharged species are assumed to have unit activity coefficients. Composition data can be input in units of molarity, or $\mathrm{mg} / \mathrm{L}$; output is in molar units. Calculated results were converted to molality units for comparison with experimental data. Corrections were less than 8 per cent at $25^{\circ} \mathrm{C}$, but were 20 30 per cent at $300^{\circ} \mathrm{C}$. Along with total concentrations of the species, estimates of the ionic strength and $\mathrm{pH}$ of the aqueous phase must be input. 
The ionic strength and $\mathrm{pH}$ can be held fixed or allowed to vary during the calculation. The partial pressure of $\mathrm{CO}_{2}$ or $\mathrm{N}_{2}$ gas can be fixed for a given calculation. No other gases are considered. The electron activity or $P E$ must be $f$ ixed if oxidation-reduction reactions are included.

\section{B. GEOCHEM}

GEOCHEM is also a modification of REDEQL2, made at the Department of Soil and Environmental Sciences of the University of California at Riverside. 5 The general features and method of calculation of GEOCHEM are similar to those of REDEQL.EPAK. The basic differences between the two programs, as far as calculations reported here are concerned, are in the thermodynamic data base, the activity-coefficient calculation, and the limitation of GEOCHEM to $25^{\circ} \mathrm{C}$. Thermodynamic data for 36 metals and 69 ligands are available in the version employed for these tests. Although most of the metals and ligands are the same as those covered in REDEQL.EPAK, the thermodynamic data are generally different. Activity coefficients are calculated using the equation

$$
-\log _{10^{\gamma}(Z)}=\frac{A Z^{2}(I)^{1 / 2}}{1+a B(I)^{1 / 2}}+B^{\circ} I
$$

where $A=0.5116, B=0.3292 \times 10^{8}$, and $a$ and $B^{\circ}$ are specified as noted below. 5 for $I \leq 0.5$ molar, $a=1 / B$ and $B^{\circ}=0.3 A Z^{2}$; this reduces to a variant of the Davies equation. For $I>0.5$ molar, $B^{\circ}$ $=0.41$ and $a=4 \times 10^{-8}, 5 \times 10^{-8}$ and $6 \times 10^{-8}$ for monovalent, divalent, and trivalent jons, respectively. Activity coefficients for $\mathrm{H}^{+}$are taken as $1 / 2 \log _{10} r(Z=1)$. The two equations do not give the same activity coefficient at $I=0.5$. For neutral ions, $B^{\circ}=0.1$ for all values of $I$; only the linear term in I contributes to $\gamma$ for neutral species. Data are input and output in molar units. As with REDEQL.EPAK, calculated results from GEOCHEM were converted to molality units for comparison with experimental data. In addition to ionic strength and $\mathrm{pH}$ estimates, a measure of the total $\mathrm{H}^{+}$(free and combined) must be input. 5 The partial pressure of $\mathrm{CO}_{2}$ and $\mathrm{N}_{2}$ can be fixed; no other gases are considered. The electron activity or $\mathrm{PE}$ must, be fixed if oxidation-reduction reactions are included.
C. WATEQF

WATEQF is a FORTRAN version of the WATEQ program prepared at the US Geological Survey in Reston, Virginia. 6 The program calculates the equilibrium distribution of species in an aqueous system. It differs from the other three programs involved in this test in that it does not determine the actual amount of particular solid phases that are formed; it calculates the distribution of species as if no solid phases were formed and indicates the state of saturation of the solution for possible solid phases contained in the data base. Complex formation, oxidation-reduction reactions, and the presence of a gas phase are considered. The set of mass-balance and massaction equations is solved by iteration. ${ }^{9}$ These equations have been rearranged to express each free-ion concentration in terms of other ion concentrations, activity coefficients, and equilibrium constants. With this method, the internal construction of the program is intimately connected to the chemistry of the species considered. Total concentrations of the various species are employed as initial estimates. : Thermodynamic data for almost 200 complexes, solids, and gases are available with the version used for these tests. Most of these species have the data needed to estimate equilibrium constants as a function of temperature. Activity coefficients are determined in a number of ways. ${ }^{6,9}$ Eight species employ Eq. (2), where $a$ and $B^{\circ}$ have been estimated from experimental data. The parameters $A$ and $B$ are calculated as a function of temperature. Activity coefficients for these eight species are always calculated in this manner. The remainder of the charged species uses Eq. (2) with $B^{0}=0$ and a ranging from 2.5-9 $x$ $10^{-8}$, depending on the species. ${ }^{9}$ These are called Debye-Huckel activity coefficients. A variant of the Davies equation,

$$
-\log _{10} \gamma(Z)=A Z^{2}\left[\frac{(I)^{1 / 2}}{1+(I)^{1 / 2}}-0.3 I\right] \text {, }
$$

can also be employed for these species. For neutral species, the activity coefficient is calculated as $\log _{10} \gamma=0.1 \mathrm{I}$. 
Composition data can be input in units of $\mathrm{meq} / \mathrm{L}, \mathrm{mg} / \mathrm{L}$, ppm, or molality; output is in ppm and molality. Results in units of molality were used directly for WATEQF. Along with total concentrations of species, the $\mathrm{pH}$ of the solution must be input. The calculation is performed at constant $\mathrm{pH}$. The partial pressures of $\mathrm{CO}_{2}$, $0_{2}$, and $\mathrm{CH}_{4}$ are calculated if these gases are present. If oxidation-reduction reactions are included, one of a number of possible measures of the electron activity must be input. 6

Because WATEQF does not determine the amounts of solid phases that are formed, it is not directly suitable for modeling precipitation in geothermal systems. The systems modeled here were all very simple, with only one precipitate; calculations with WATEQF were relatively easy for these systems. It was necessary to adjust total concentrations of ions contributing to the precipitate in each case so that the solution was just at saturation to obtain the correct ionic strength and activity coefficients. This process required a few repeated calculations for each case. The $\mathrm{pH}$ used was estimated from results for other programs. Additional problems were encountered for the $\mathrm{CaCO}_{3}$ solubility calculations where a specific $\mathrm{CO}_{2}$ pressure was desired. The other three programs allow a $\mathrm{CO}_{2}$ pressure or its equivalent for these simple systems to be specified; with WATEQF, the $\mathrm{CO}_{3}^{-2}$ total concentration must be adjusted to achieve the desired $\mathrm{CO}_{2}$ pressure. In spite of the difficulties, WATEQF was included in these tests because it is widely used and has a well-documented thermodynamic data base.

\section{SENECA2}

SENECA2 is a modification of SENECA made at the Los Alamos National Laboratory. SENECA was originally written by $\mathrm{Ma}$ and Shipman; ${ }^{7}$ it computes equilibrium compositions in a two-step process. The first step uses the free-energy minimization procedure proposed by Naphtali to obtain an approximate composition for a system. 10 The second step uses this approximate composition as an initial estimate for solving the set of massbalance and mass-action equations by the NewtonRaphson method. 2

The modifications made at Los Alamos included a permanent arrangement for an aqueous phase, a gas phase, and multiple solid phases; an activity coefficient calculation for aqueous species, oxidation-reduction reactions, and a thermodynamic data base. The solid phases present are determined during the first step of the calculation. They are added or rejected during free-energy minimization as successively better estimates of the composition are obtained. Solid phases can be rejected during the second step, but no new solid phases can be added.

Thermodynamic data for 70 complexes, gases, and solids of interest in geothermal systems are available with the version used for these tests. Free-energy data from 25 to $300^{\circ} \mathrm{C}$ were obtained from Helgeson.11-13 Activity coefficients for charged species are calculated using Eq. (2), where $A, B$, and $B^{\circ}$ are calculated as functions of temperature. 11 Values of the parameter a ranging from 2.5-9 $\times 10^{-8}$ are used for the various ions and complexes. 3 The activity of water is determined from data on the osmotic coefficient. 11 The activity coefficients of neutral species are calculated from the activity coefficient of $\mathrm{CO}_{2}$ in $\mathrm{NaCl}$ solutions. 11 Composition data are input and output in units of molality. Only temperature and total pressure are required input data along with the total concentrations of the species defining the solution. Potential solid phases, gas phases, and complexes to be considered during the calculation are not automatically selected from the data base by SENECA2 as with the other three programs. A list specifying which species are to be considered must be input. If a gas phase $\left(\mathrm{CO}_{2}\right.$ or $\mathrm{H}_{2} \mathrm{~S}$ are in the data base $)$ is present at equilibrium, water vapor at its equilibrium vapor pressure is included as one of the components. If oxidation-reduction reactions are included, the solution $E_{h}$, the oxygen partial pressure, or the sulfate-sulfide ratio must be specified to set the electron activity.

\section{II. EXPERIMENTAL DATA FOR TEST CASES}

Seven test cases were chosen for which calculated results from the four chemical-equilibrium codes could be compared with experimental data. Each of the cases involves precipitation of a single solid phase from water, an $\mathrm{NaCl}$, or an $\mathrm{HCl}$ solution (up to 4 molal). Solution temperatures 
ranged from $25-300^{\circ} \mathrm{C}$. Table I summarizes the conditions employed for the seven cases. The following sections discuss each of the test cases and the sources of the experimental data. For each test case, the experimental data are plotted and a smoothed curve drawn through the data. The smoothed curves were employed for later comparison with the calculated results. The plots are presented to establish the magnitude of scatter or uncertainty in the experimental data. This experimental uncertainty can be compared with the differences between the calculated results and experimental curves in Sec. IV.

\section{A. Test Case 1}

The first test case involved the solubility of $\mathrm{CaCO}_{3}$ in 0-4-molal $\mathrm{NaCl}$ solutions at $25^{\circ} \mathrm{C}$ and 1-atm $\mathrm{CO}_{2}$ pressure. Data were obtained from four sources. 14-17 Figure 1 shows a plot of the data as a function of total $\mathrm{NaCl}$ content of the solution. The solid line represents a smoothed curve through the data. Two of the four sources identified the solid phase as calcite; ${ }^{15,16}$ the other two sources mentioned only $\mathrm{CaCO}_{3}$. The data of Cameron, et al., were considered unreliable by Frear and Johnston. 15 However, they represent the only data available at high ionic strength.

\section{B. Test Case 2}

The second test case involved the solubility of $\mathrm{CaCO}_{3}$ in water at $25-300^{\circ} \mathrm{C}$ and 1 -atm $\mathrm{CO}_{2}$ pressure. Data were obtained from three sources. $15,18,19$ Figure 2 shows a plot of the data as a function of temperature. The solid line represents a smoothed curve through the data. A11 three sources identified the solid phase as calcite.

TABLE I

\section{TEST CASES}

\begin{tabular}{|c|c|c|c|c|}
\hline $\begin{array}{l}\text { Test } \\
\text { Case } \\
\end{array}$ & Precipitate & Solution & $\begin{array}{c}\text { Temperature } \\
\mathrm{C} \\
\end{array}$ & Remarks \\
\hline 1 & $\mathrm{CaCO}_{3}$ & $0-4 \geq \mathrm{NaCl}$ & 25 & $1 \mathrm{~atm} \mathrm{CO}$ \\
\hline 2 & $\mathrm{CaCO}_{3}$ & water & $25-300$ & $1 \mathrm{~atm} \mathrm{CO}_{2}$ \\
\hline 3 & $\mathrm{CaCO}_{3}$ & 1 m NaCl & $25-300$ & $12 \mathrm{~atm} \mathrm{CO}$ \\
\hline 4 & $\mathrm{SiO}_{2}$ & water & $25-200$ & - \\
\hline 5 & $\mathrm{SiO}_{2}$ & $0-4 \underline{m ~ H C l}$ & 25 and 90 & $\therefore$ \\
\hline 6 & $\mathrm{BaSO}_{4}$ & $0-4 \underline{m ~ N a C l}$ & 25 and 95 & - \\
\hline 7 & $\mathrm{CaSO}_{4}$ & $0-4 \underline{m ~ N a C l}$ & $\begin{array}{l}25,100 \text { and } \\
250\end{array}$ & - \\
\hline
\end{tabular}

C. Test Case 3

The third test case involved the solubility of $\mathrm{CaCO}_{3}$ in a 1-molal $\mathrm{NaCl}$ solution at $100-300^{\circ} \mathrm{C}$ and $12-\mathrm{atm} \mathrm{CO}_{2}$ pressure. Data were available from only one source. ${ }^{18}$ Figure 3 shows a plot of the data as a function of temperature. The solid line represents a smoothed curve through the data. The solid phase was calcite. These data are from the same source as the high-temperature data in Test Case 2.

\section{Test Case 4}

The fourth test case involved the solubility of amorphous $\mathrm{SiO}_{2}$ in water at $25-200^{\circ} \mathrm{C}$. Data were obtained from three sources. ${ }^{20-22}$ One was a composite curve generated from a number of earlier investigations. 20 Figure 4 shows a plot of the data as a function of temperature. The solid line represents a smoothed curve through the data. The agreement among the various investigators is generally quite good.

E. Test Case 5

The fifth test case involved the solubility of amorphous $\mathrm{SiO}_{2}$ in 0-4-molal $\mathrm{HCl}$ solutions at 25 and $90^{\circ} \mathrm{C}$. Data from only one source were found. 23 Figure 5 shows a plot of the data as a function of total $\mathrm{HCl}$ content of the solution. The solid lines represent smoothed curves through the data. The data for water (0-molal $\mathrm{HCl})$ are a little above the experimental curve in Fig. 4.

\section{F. Test Case 6}

The sixth test case involved the solubility of $\mathrm{BaSO}_{4}$ (barite) in 0-4-molal $\mathrm{NaCl}$ solutions at 25 and $95^{\circ} \mathrm{C}$. Data from two sources were employed. 24,25 Figure 6 shows a plot of the data as a function of total $\mathrm{NaCl}$ content of the solution. The solid lines represent smoothed curves through the data. The systematic difference between the data of Templeton and Blount necessitated a rather arbitrary line. This uncertainty, however, was not significant in comparison with the scatter in calculated results.

G. Test Case 7

The seventh test case involved the solubility of $\mathrm{CaSO}_{4}$ in 0-4-molal $\mathrm{NaCl}$ solutions at 25, 100, and $250^{\circ} \mathrm{C}$. Data from three sources were used. 26-28 Figure 7 shows a plot of the data as a function of total $\mathrm{NaCl}$ content of the solution. The solid lines represent smoothed curves through 


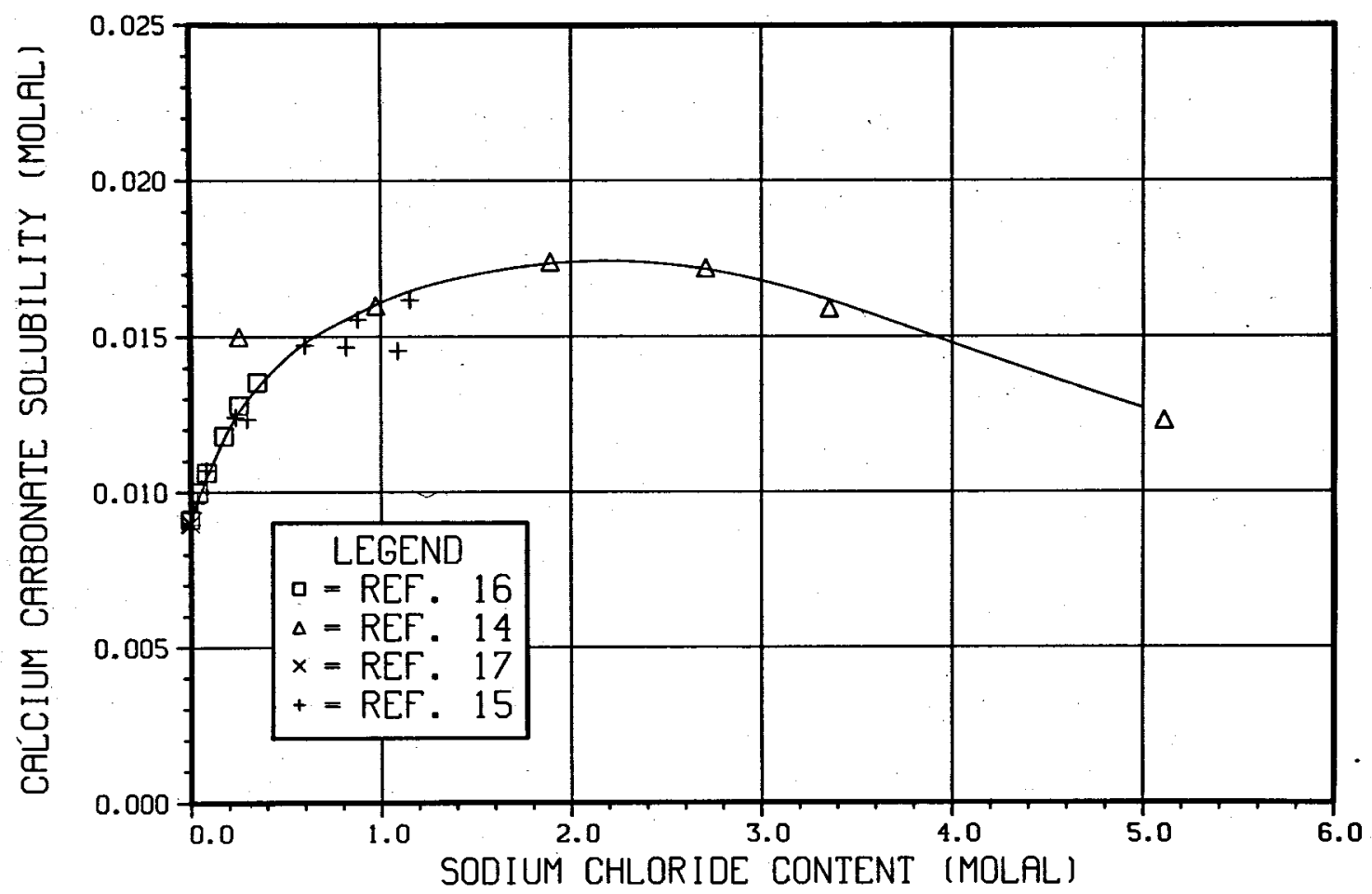

Fig. 1. Experimental data for Test Case 1.

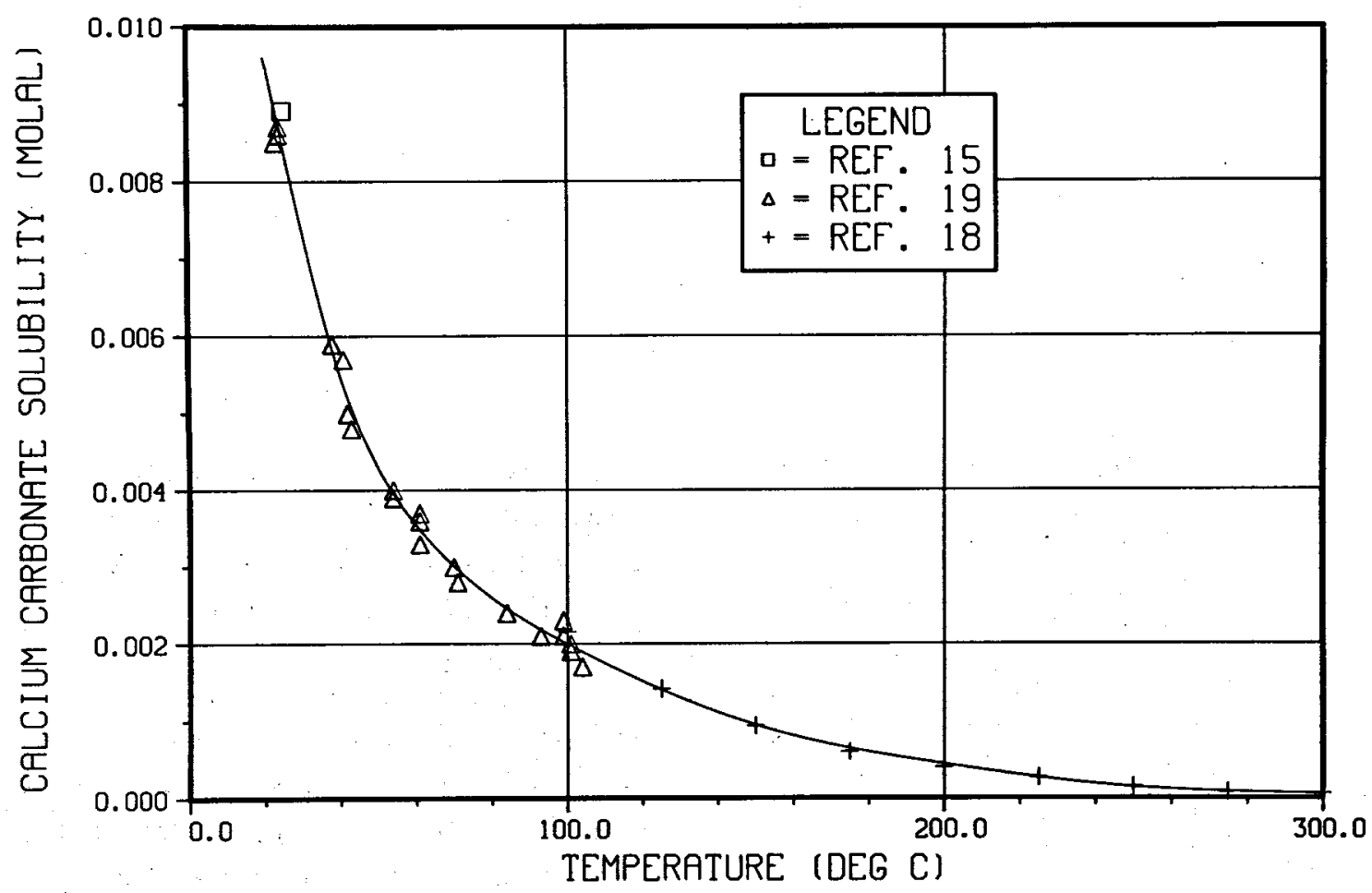

Fig. 2. Experimental data for Test Case 2. 


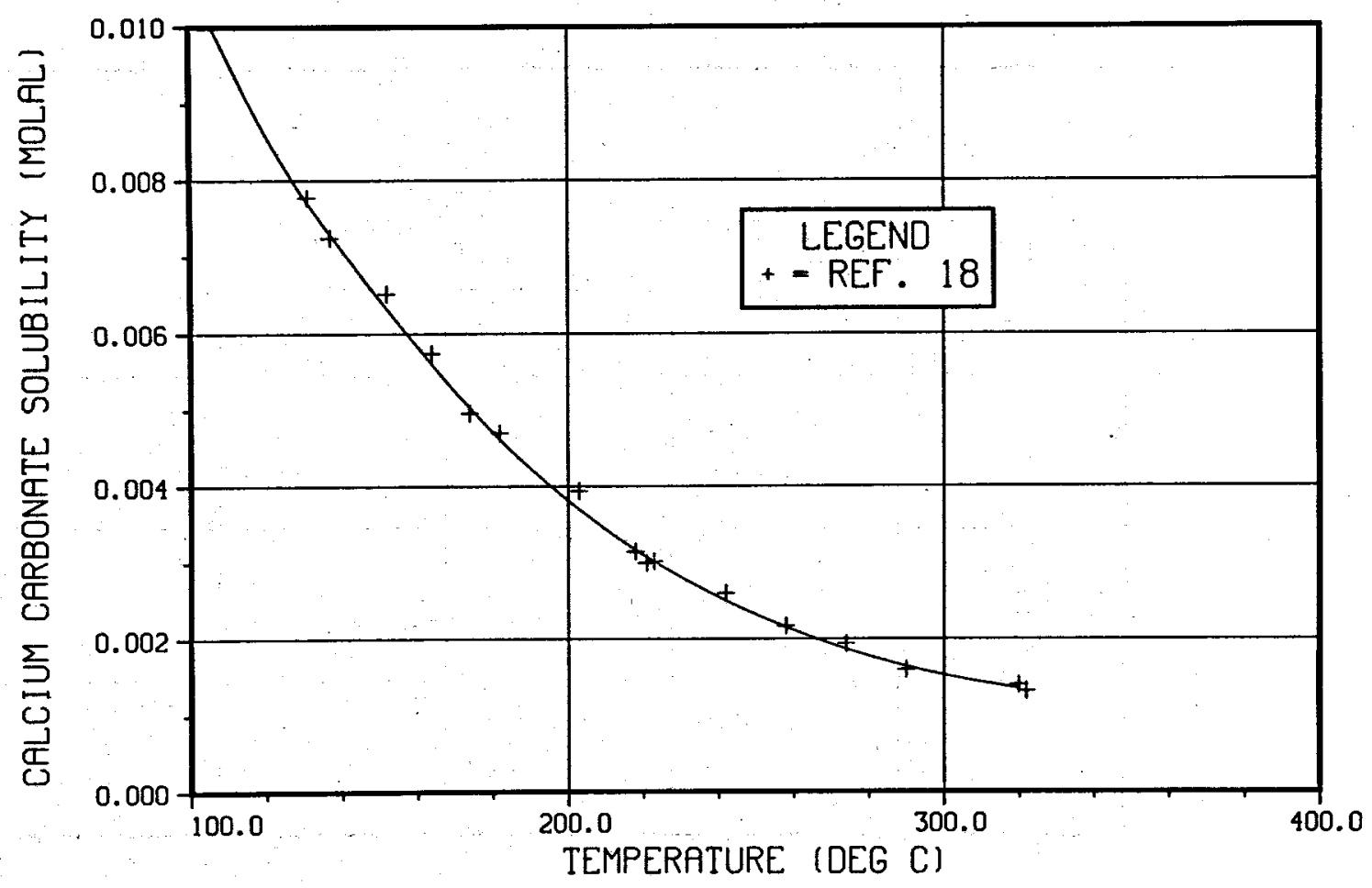

Fig. 3. Experimental data for Test Case 3.

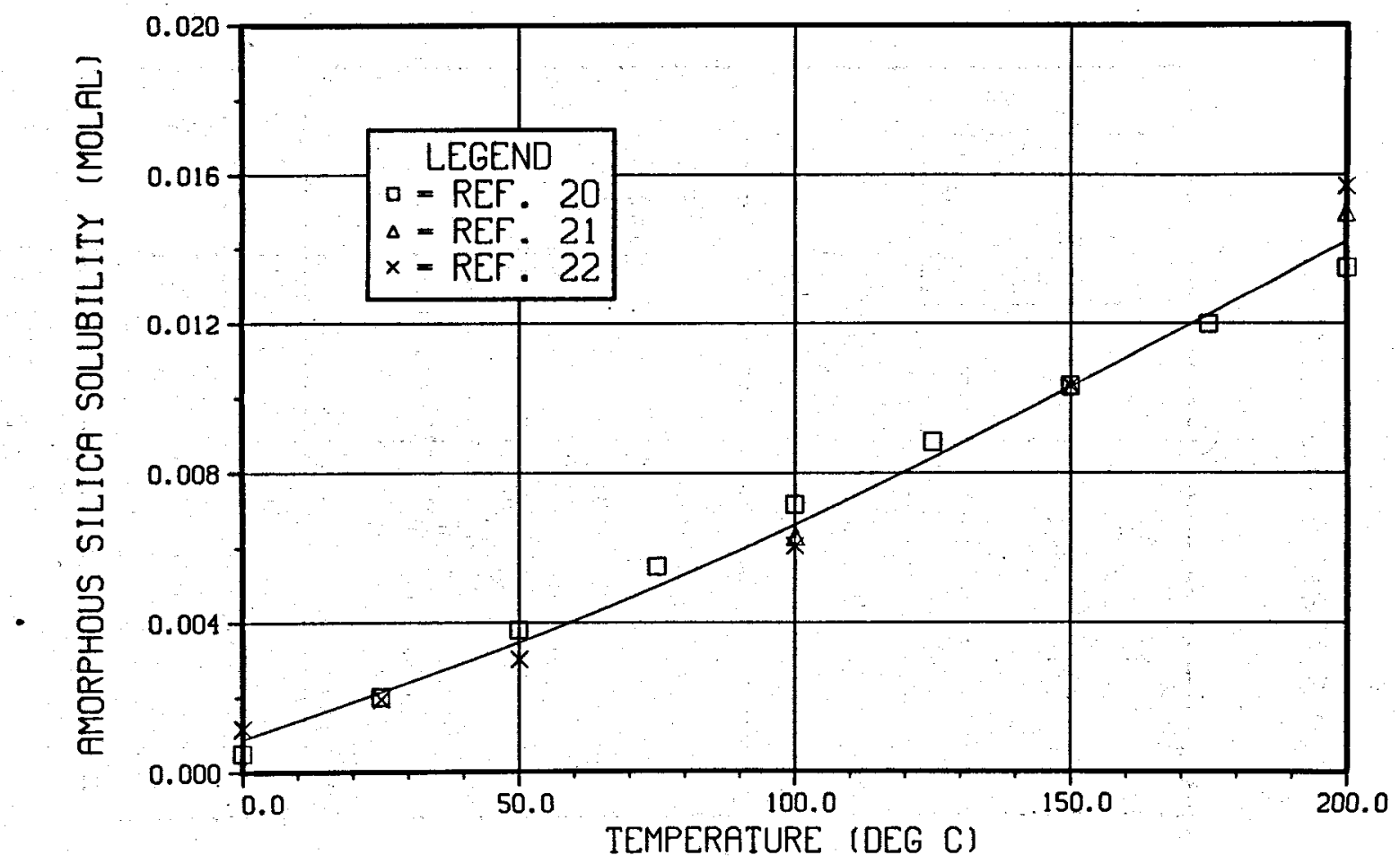

Fig. 4. Experimental data for Test Case 4. 


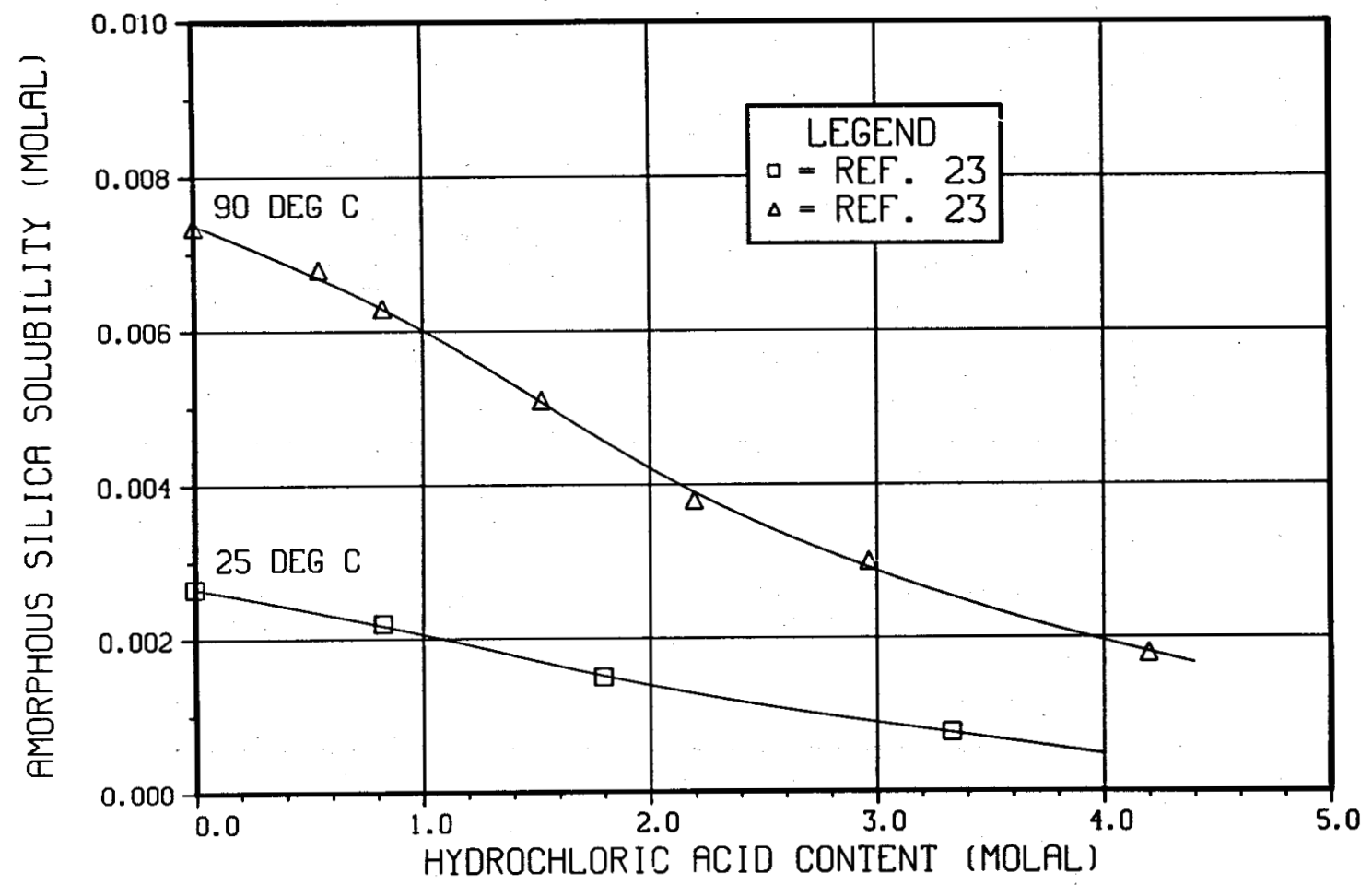

Fig. 5. Experimental data for Test Case 5.

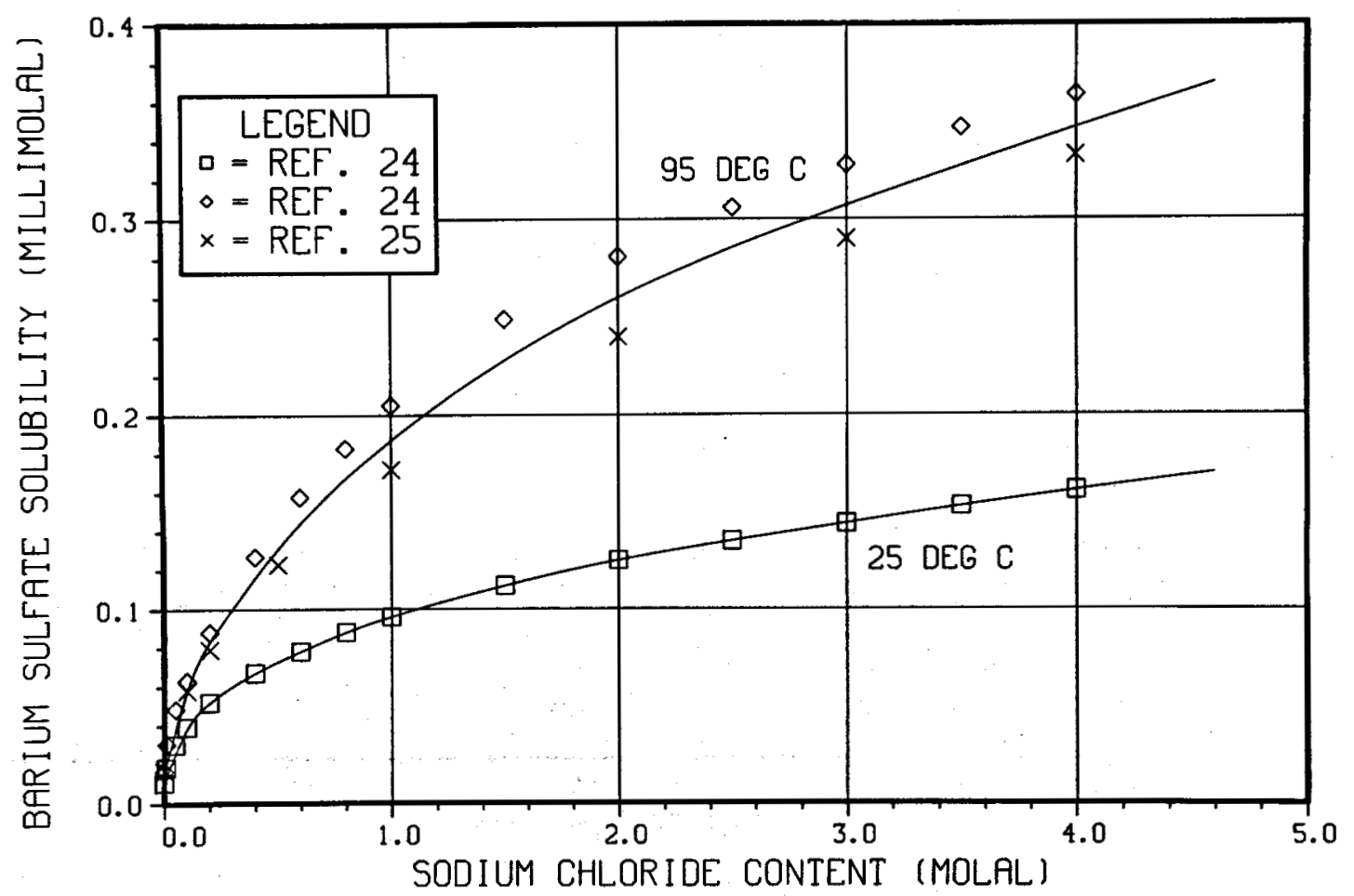

Fig. 6. Experimental data for Test Case 6. 


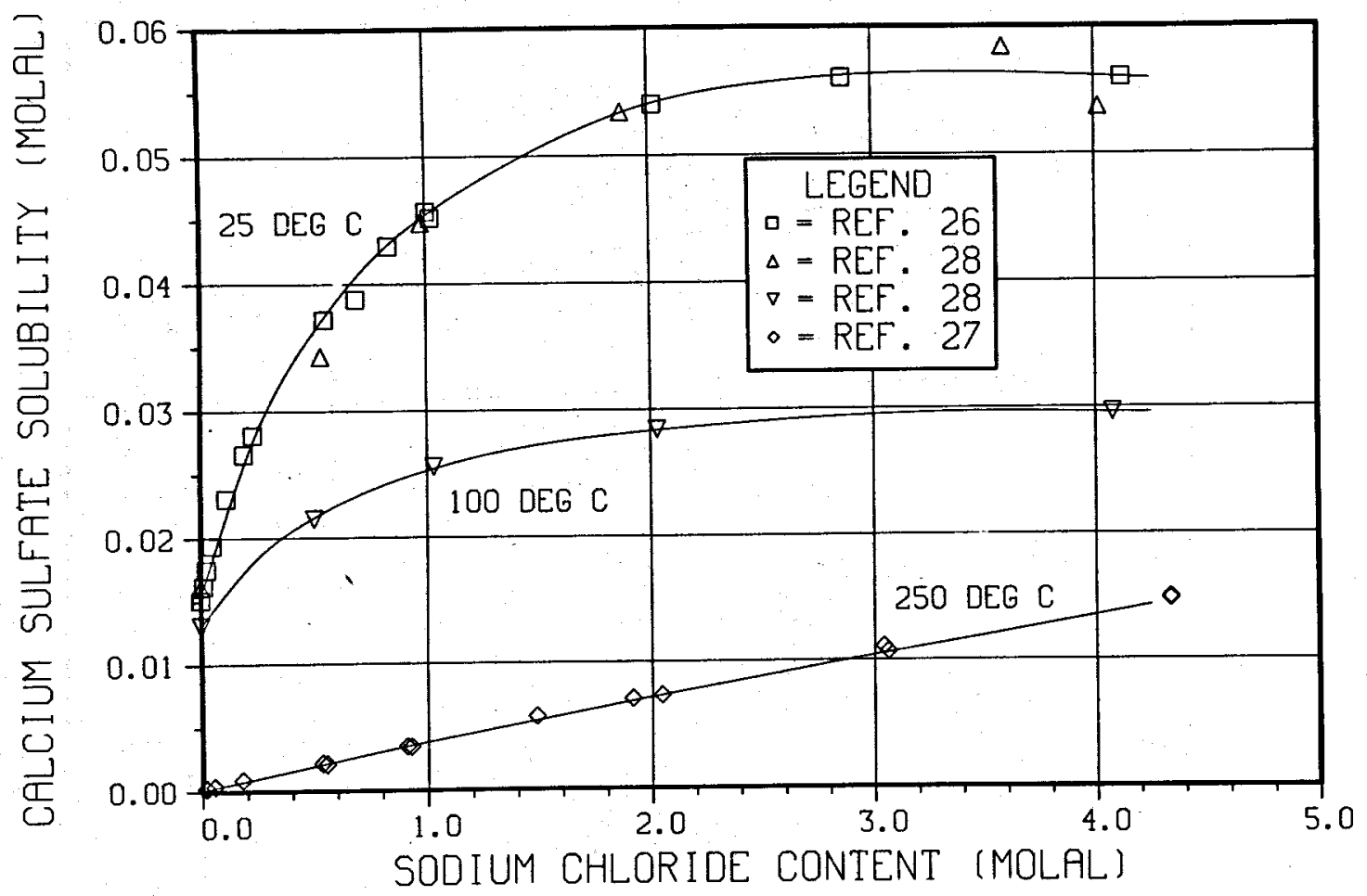

Fig. 7. Experimental data for Test Case 7.

the data. At $25^{\circ} \mathrm{C}$, the data are for gypsum; at 100 and $250^{\circ} \mathrm{C}$, the data are for anhydrite.

\section{TEST CASE RESULTS}

An attempt was made to use each of the four chemical-equilibrium computer programs to calculate the solubility of the solid phase for each test case. In some instances, the limitations of the program precluded its use; for example, GEOCHEM is usable only at $25^{\circ} \mathrm{C}$. The following sections discuss the results for each of the test cases.

Two of the programs (REDEQL.EPAK and GEOCHEM) deal in molarity units, but the experimental data are all in molality units. Considering the uncertainty in equilibrium constants and activity coefficients, the differences between molality and molarity are often ignored. For the comparisons reported here, results from the two codes were corrected to molality units. The correction was calculated as

$$
\frac{\dot{C}_{M}}{C_{m}}=\rho_{s} W_{s} \text {, }
$$

where $C_{M}$ is the concentration in molarity units, $C_{m}$ is the concentration in molality units, " ${ }_{s}$ is the density of the solution, and $w_{s}$ is the mass of water per unit mass of solution. The quantity $w_{S}$ was determined as

$$
w_{s}=\frac{1000}{1000+M_{s} C_{m}} \text {, }
$$

where $M_{s}$ is the molecular weight of the solute. For these calculations, $M_{s}$ was taken as the molecular weight of $\mathrm{NaCl}, 58.44$. The density of the solution at the temperature of the test and $C_{m}$ molality was calculated from the correlation of Haas. 29 Figure 8 shows a plot of the molarity/molality ratio $\left(C_{M} / C_{m}\right)$ as a function of the solution molality at various temperatures. This ratio was employed for corrections to REDEQL.EPAK and GEOCHEM results.

\section{A. Test Case 1 Results}

Figure 9 shows a plot of $\mathrm{CaCO}_{3}$ solubility as a function of total $\mathrm{NaCl}$ content of the solution for Test Case 1. The solid line is the same curve 


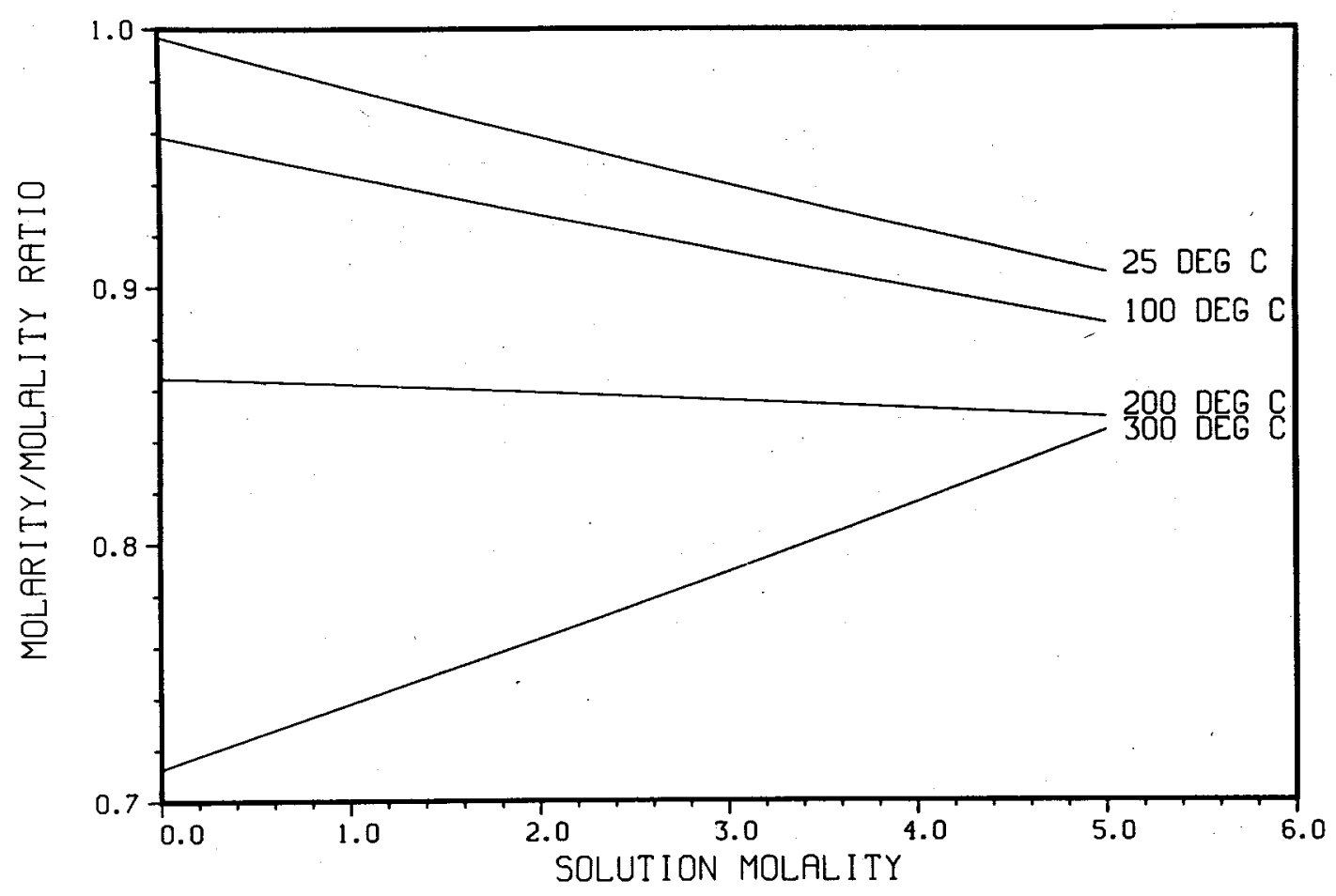

Fig. 8. Molarity-molality correction factors.

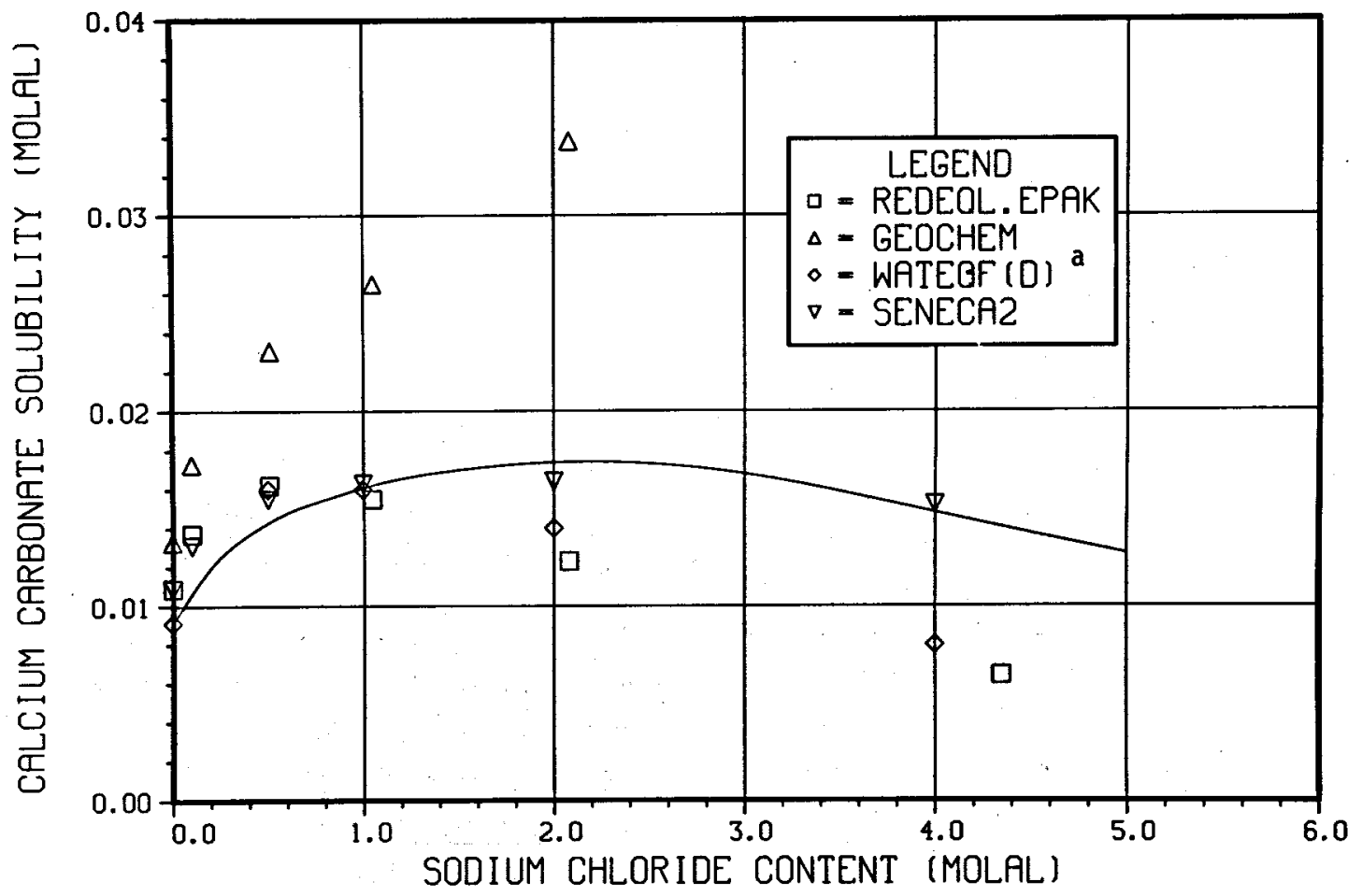

${ }^{a}$ Indicates Davies equation.

Fig. 9. Results for Test Case 1. 
that is drawn through the experimental data in Fig. 1. The results from SENECA2 are in reasonable agreement with the experimental curve over the entire range of $\mathrm{NaCl}$ content. The results from REDEQL.EPAK and WATEQF show reasonable agreement up to 1-m $\mathrm{NaCl}$ content, but drop significantly below the experimental curve at higher ionic strengths. The differences between the results from SENECA2 and the results from WATEQF and REDEQL.EPAK are mainly in the activity-coefficient calculation. The three programs agree relatively well at $0-1-\underline{m ~ N a C l}$ content, but diverge at higher values. The results from WATEQF were independent of the choice of method for calculating activity coefficients because all the influential species in the test case are members of the group whose activity-coefficient calculation does not vary. WATEQF has solubility data for both calcite and aragonite. The results reported here represent calcite solubilities. Aragonite solubility is about twice that of calcite at $25^{\circ} \mathrm{C}$.

The results from GEOCHEM are slightly high for water, but they diverge rapidly at higher $\mathrm{NaCl}$ content. One result, $0.045-\mathrm{molal}^{\mathrm{CaCO}_{3}}$ solubility at 4.35-molal $\mathrm{NaCl}$ content, was not plotted. The cause of the high solubility is consideration of the formation of the $\mathrm{CaCl}^{+}$complex by GEOCHEM. This complex contains about one-half the calcium in solution at 2-molal $\mathrm{NaCl}$ content and about twothirds of the calcium at 4-molal NaCl content. The equilibrium constant used by GEOCHEM for the reaction

$$
\mathrm{Ca}^{+2}+\mathrm{Cl}^{-}=\mathrm{CaCl}^{+}
$$

is about 4. No references were found for this formation constant. Based on results presented here, it appears to be too high. None of the other three programs consider the formation of $\mathrm{CaCl}^{+}$. Activity coefficients calculated by GEOCHEM are similar to those of SENECA2. The slight discontinuity in the GEOCHEM results between 0.5 and 1-molal $\mathrm{NaCl}$ content occurs from a change in the activity-coefficient equation in this range.

\section{B. Test Case 2 Results}

Figure 10 shows a plot of $\mathrm{CaCO}_{3}$ solubility as a function of solution temperature for Test Case 2. The solid line is the same curve as is drawn through the experimental data in Fig. 2.
GEOCHEM was not included in this comparison because it is usable only at $25^{\circ} \mathrm{C}$; Test Case 1 includes that comparison. The results from SENECA2 are a little high at $25^{\circ} \mathrm{C}$, but are generally in reasonable agreement over the entire temperature range. The results from WATEQF are in good agreement from $25-200^{\circ} \mathrm{C}$, but are somewhat high at $300^{\circ} \mathrm{C}$. Because of the necessity to $f i x \mathrm{pH}$ and the inability to fix the $\mathrm{CO}_{2}$ pressure with WATEQF, these calculations required additional time and effort. The results from REDEQL.EPAK are slightly high at $25^{\circ} \mathrm{C}$. From $100-300^{\circ} \mathrm{C}$, their trend is opposite to that of the experimental curve; that is, the calculated solubility increases with increasing temperature rather than decreasing. These problems may be related to equilibrium-constant data. The formation constant of solid $\mathrm{CaCO}_{3}$ is not available as a function of temperature in REDEQL.EPAK. Also, the temperature variation of the formation constant for $\mathrm{HCO}_{3}^{-}$(from $\mathrm{H}^{+}$and $\mathrm{CO}_{3}^{-2}$ ) appears quite different from that in WATEQF or SENECA2. Activity coefficients calculated by the three programs are in relatively good agreement for this test case because the solutions are at low ionic strength. The results from WATEQF were independent of the choice of activity-coefficient calculation.

\section{Test Case 3 Results}

Figure 11 shows a plot of $\mathrm{CaCO}_{3}$ solubility as a function of solution temperature for Test Case 3. The solid line is the same curve as is drawn through the experimental data in Fig. 3. Only results from WATEQF and SENECA2 are included because GEOCHEM is usable only at $25^{\circ} \mathrm{C}$ and REDEQL.EPAK does not allow $\mathrm{CO}_{2}$ pressures above 1 atm. The $\mathrm{CO}_{2}$ pressure was $12 \mathrm{~atm}$ for this test case. The SENECA2 results are high at $100^{\circ} \mathrm{C}$, but those at $200-300^{\circ} \mathrm{C}$ are in reasonable agreement with the experimental curve. The WATEQF results are quite low at $100^{\circ} \mathrm{C}$ and appear to be increasing with increasing temperature at $200-300^{\circ} \mathrm{C}$. Again, difficulties were encountered in obtaining results with WATEQF. A number of differences in equilibrium-constant data appear to be the cause of the differences between SENECA2 and WATEQF. Activity coefficients were similar for the two programs.

\section{Test Case 4 Results}

Figure 12 shows a plot of amorphous $\mathrm{SiO}_{2}$ solubility as a function of temperature for Test 


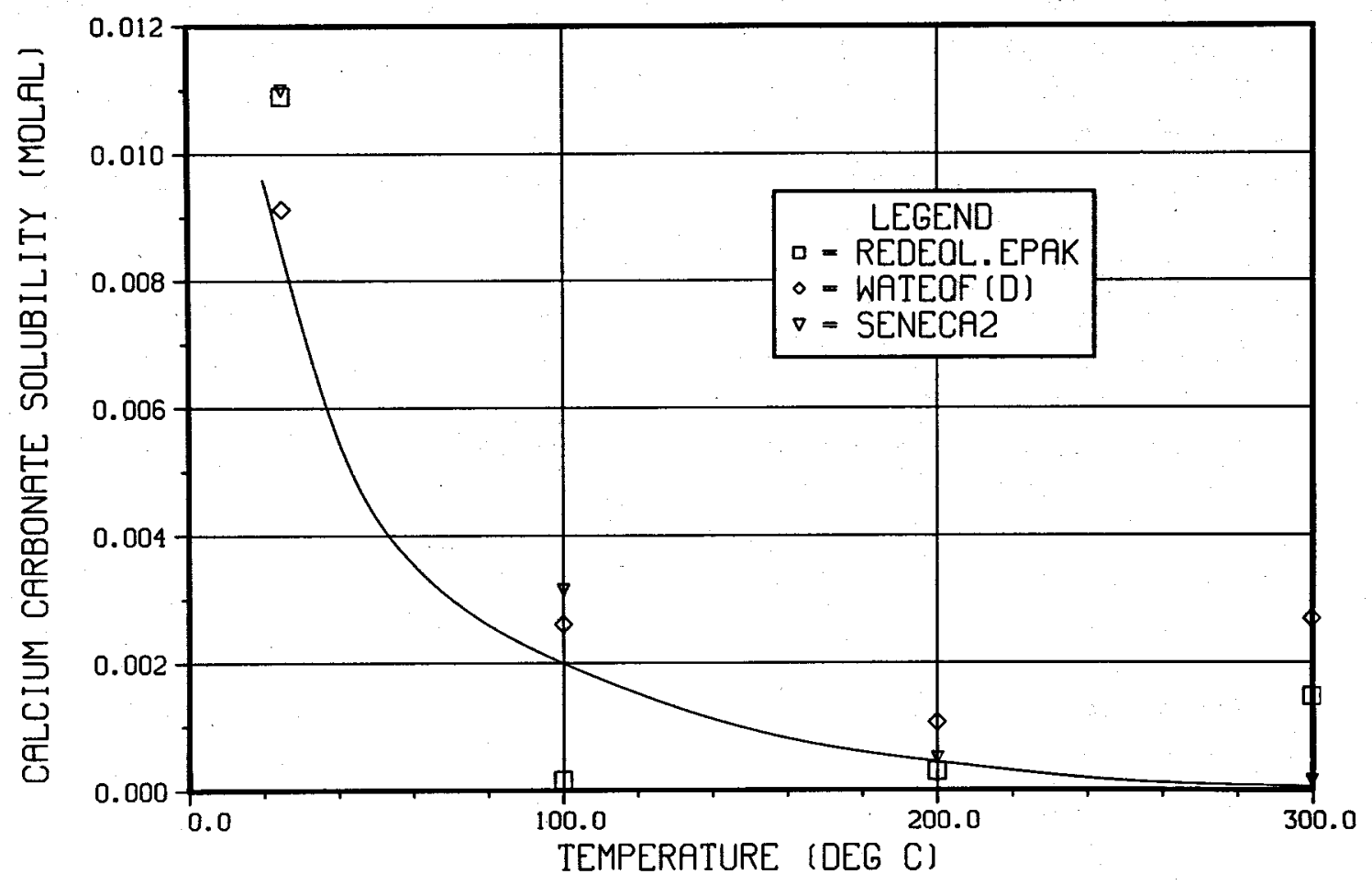

Fig. 10. Results for Test Case 2.

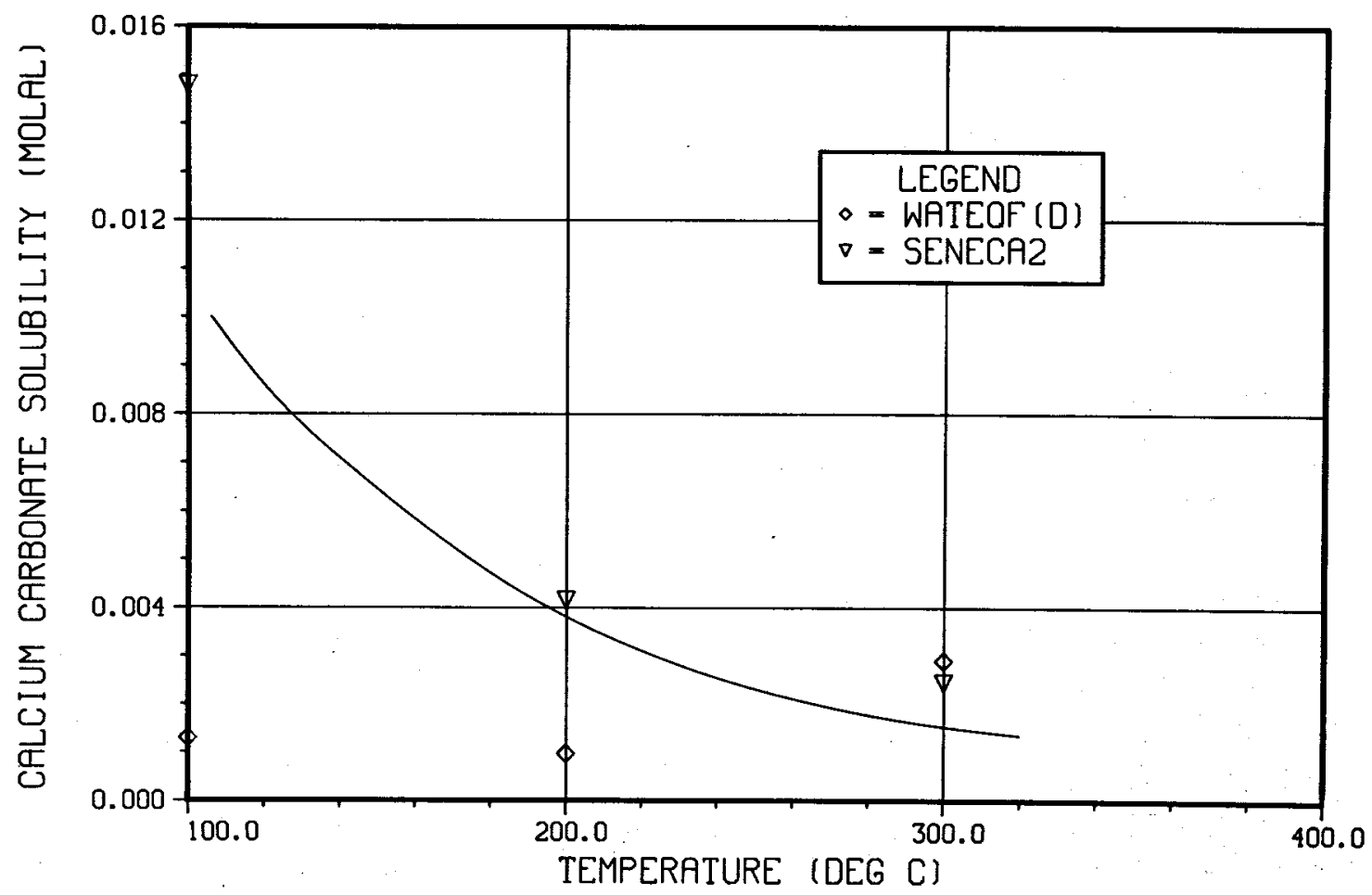

Fig. 11. Results for Test Case 3 . 


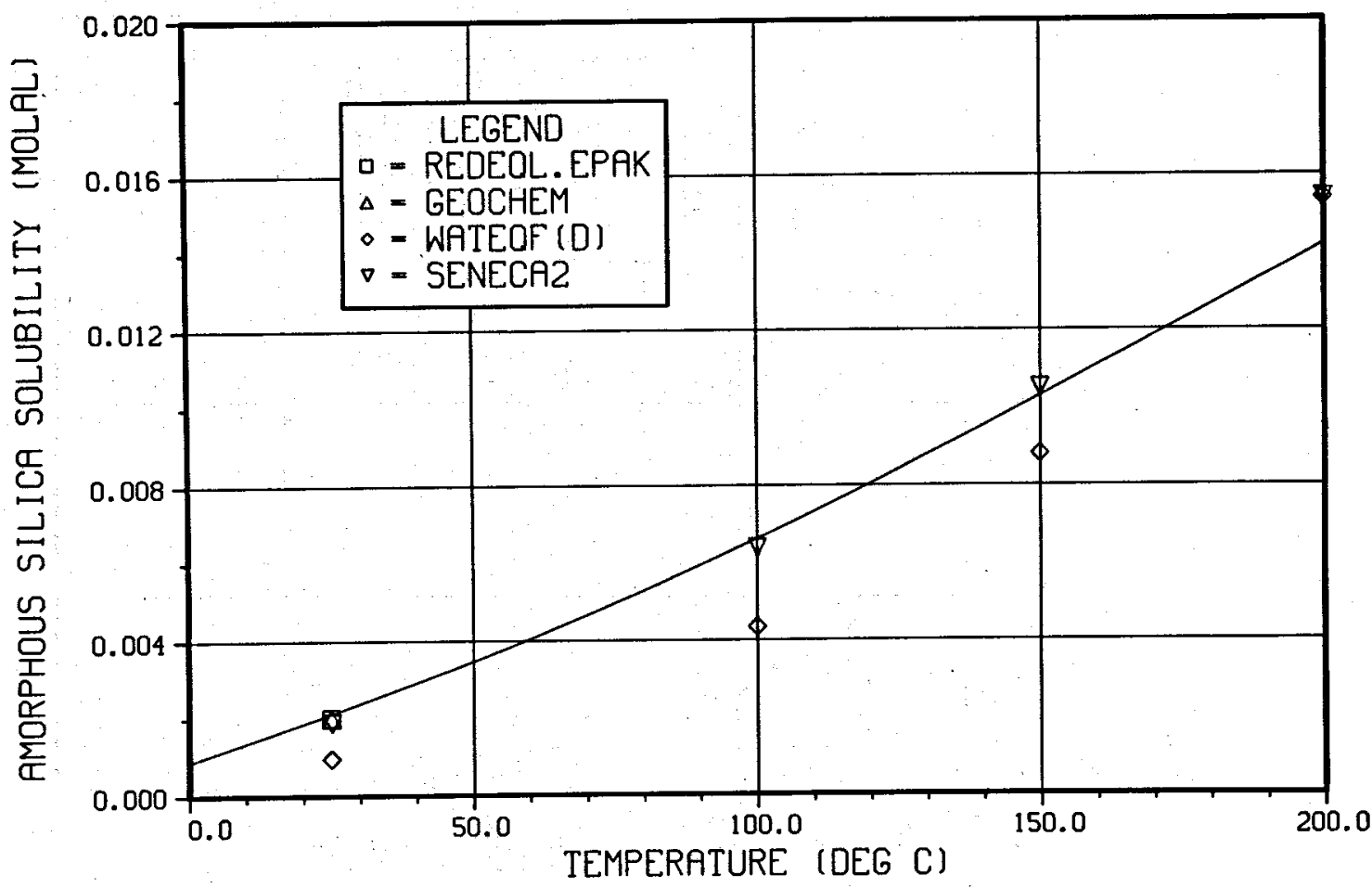

Fig. 12. Results for Test Case 4.

Case 4. The solid line is the same curve as is drawn through the experimental data in Fig. 4. GEOCHEM and REDEQL.EPAK data are shown for $25^{\circ} \mathrm{C}$ only; REDEQL.EPAK does not have data for the temperature variation of the formation constant of amorphous silica. The results of all four programs are in relatively good agreement with the experimental curve for this test case. WATEQF has solubility data for a number of solid $\mathrm{SiO}_{2}$ phases. ${ }^{6}$ The results in Fig. 12 are for the "silglas" phase, which gave the best overall agreement with the experimental curve. The "silgel" phase showed better agreement at $25^{\circ} \mathrm{C}$, but was quite high at $100-200^{\circ} \mathrm{C}$. The activity coefficients for the significant species were similar from all four programs owing to the low ionic strengths involved.

\section{E. Test Case 5 Results}

Figure 13 shows a plot of amorphous $\mathrm{SiO}_{2}$ solubility as a function of total $\mathrm{HCl}$ content of the solution at $25^{\circ} \mathrm{C}$ for Test Case 5. The solid line is the same curve as is drawn through the experimental data at $25^{\circ} \mathrm{C}$ in Fig. 5. Figure 14 shows a similar plot for the $90^{\circ} \mathrm{C}$ data.
At $25^{\circ} \mathrm{C}$ (Fig. 13), the results of GEOCHEM and SENECA2 are in good agreement with the experimental curve. The results of REDEQL.EPAK are also in relatively good agreement, but they are almost constant with increasing $\mathrm{HCl}$ content rather than decreasing as the experimental curve does. This is because the precipitation reaction for $\mathrm{SiO}_{2}$,

$$
\mathrm{H}_{4} \mathrm{SiO}_{4(\mathrm{aq})}=\mathrm{SiO}_{2(\mathrm{~s})}+2 \mathrm{H}_{2} \mathrm{O}
$$

involves only neutral species, and REDEQL.EPAK assumes neutral species have unit activity coefficients at all ionic strengths. ${ }^{4}$ The results from WATEQF (using the "silglas" solid) are low over the entire range.

At $90^{\circ} \mathrm{C}$ (Fig. 14), only results from SENECA2 and WATEQF were available. These results are low except at the highest $\mathrm{HCl}$ content. The Davies equation was used for the WATEQF activity coefficients. Because the major species are neutral in this test case, the choice of activity-coefficient method in WATEQF is immaterial. 


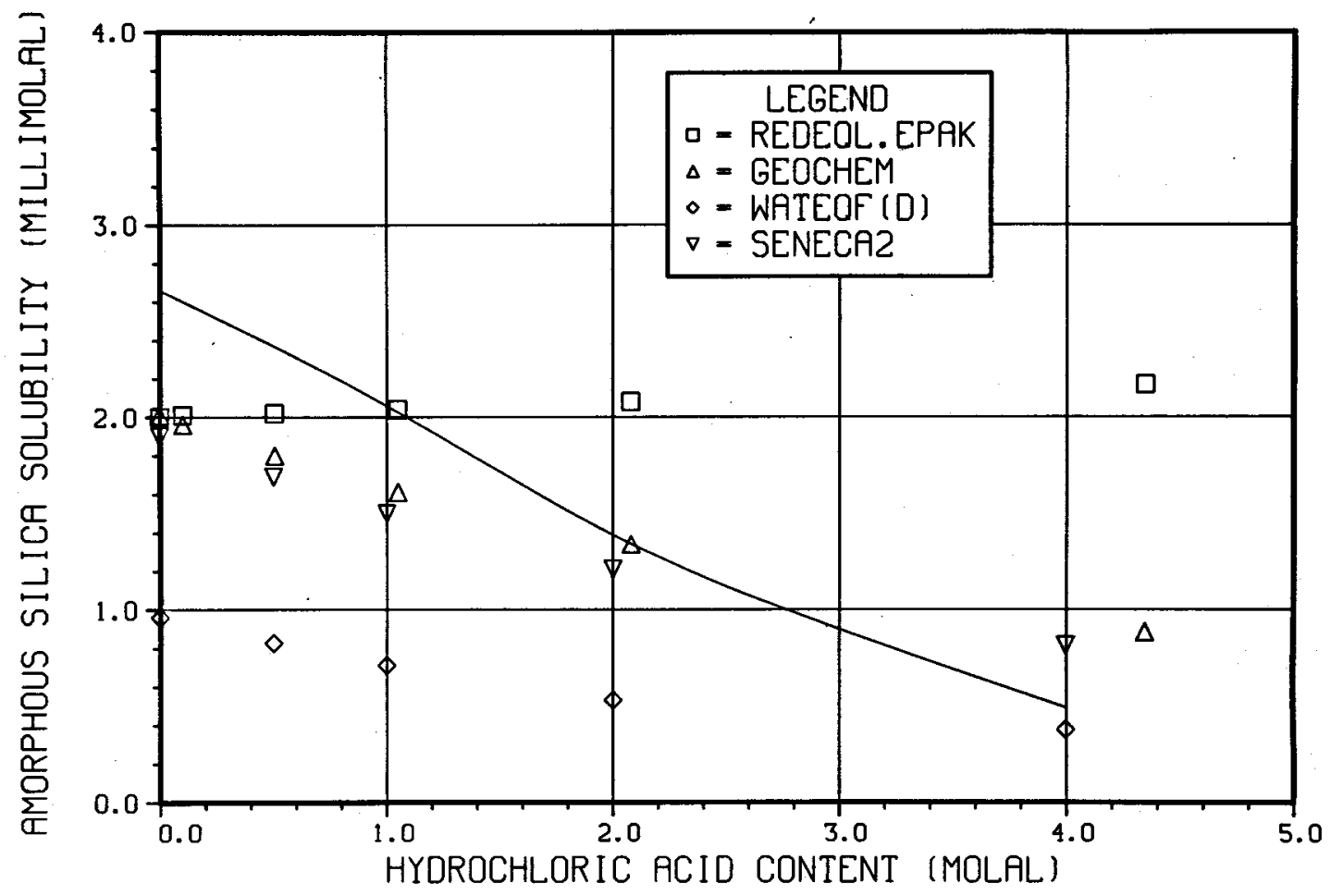

Fig. 13. Results for Test Case 5 at $25^{\circ} \mathrm{C}$.

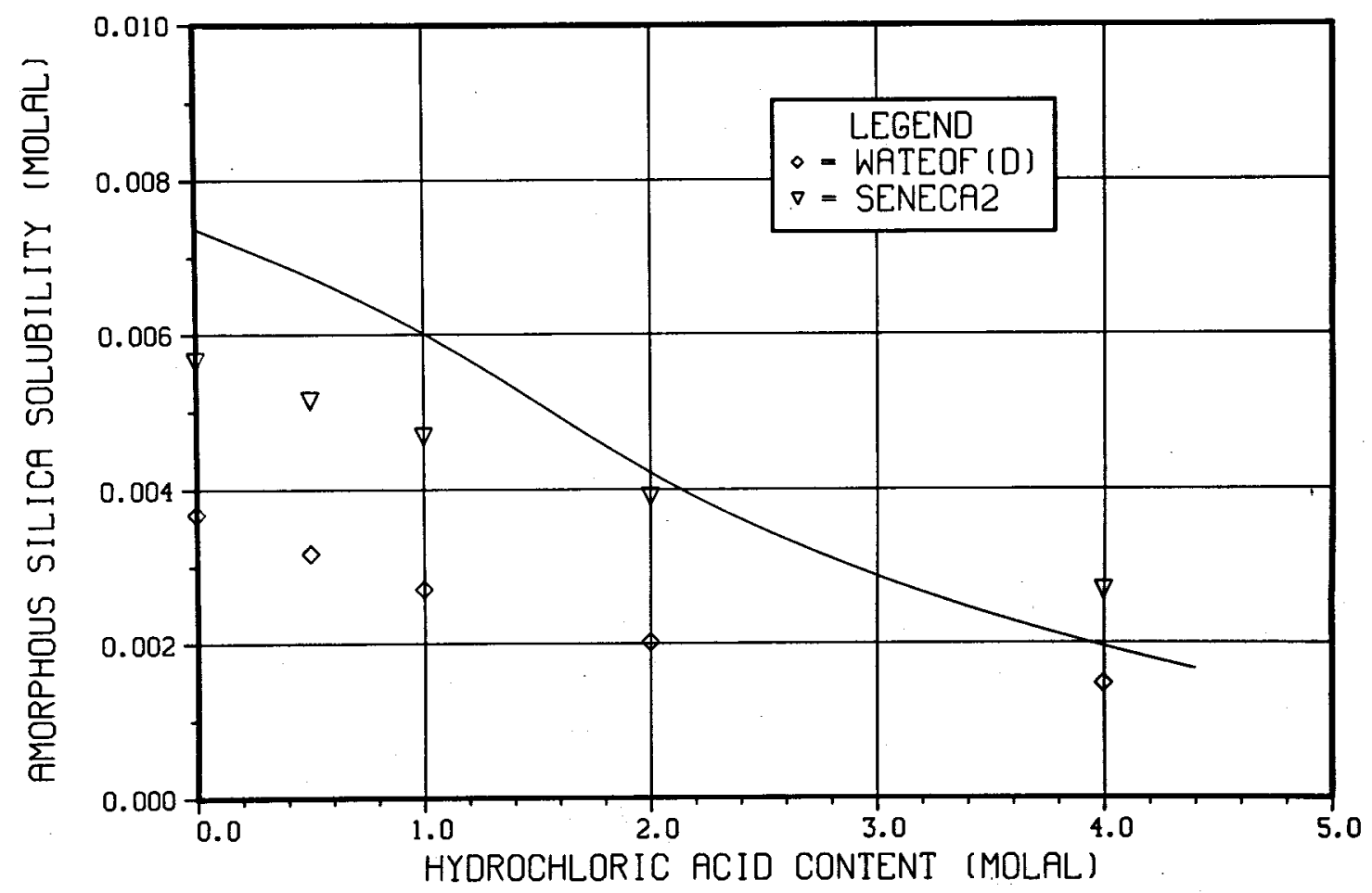

Fig. 14. Results for Test Case 5 at $90^{\circ} \mathrm{C}$. 


\section{F. Test Case 6 Results}

Figure 15 shows a plot of $\mathrm{BaSO}_{4}$ solubility as a function of total $\mathrm{NaCl}$ content of the solution at $25^{\circ} \mathrm{C}$ for Test Case 6 . The solid line is the same curve as is drawn through the experimental data at $25^{\circ} \mathrm{C}$ in $\mathrm{Fig} .6$. Figure 16 shows a similar plot for the $95^{\circ} \mathrm{C}$ data.

At $25^{\circ} \mathrm{C}$ (Fig. 15 ), the results of SENECA2 are in good agreement with the experimental curve. Two sets of results are shown for WATEQF, one using Davies equation activity coefficients and the other using Debye-Huckel equation activity coefficients. Both methods give similar results at 0-0.5-molal $\mathrm{NaCl}$ content; above that range, results employing the Debye-Huckel activity coefficients show much better agreement with the experimental curve. The results of REDEQL.EPAK are similar to those of WATEQF with the Davies equation activity coefficients. Both problems come from activity coefficients that are too large at high ionic strengths. For REDEQL.EPAK, both $\mathrm{Ba}^{+2}$ and $\mathrm{SO}_{4}^{-2}$ activity coefficients are high. For WATEQF, the Davies equation activity coefficient for $\mathrm{Ba}^{+2}$ is much too large; the $\mathrm{SO}_{4}{ }^{-2}$ activity coefficient is always calculated with the same equation. The GEOCHEM results are quite low over the entire range of $\mathrm{NaCl}$ contents. This is because of a significant difference in the formation constant for solid $\mathrm{BaSO}_{4}$ in GEOCHEM as compared with the other three programs; it is about an order of magnitude larger.

At $95^{\circ} \mathrm{C}$ (Fig. 16), the results of SENECA2 are in good agreement with the experimental curve at low ionic strengths, but are high above 1-molal $\mathrm{NaCl}$ content. For WATEQF, the results using Davies equation activity coefficients are as low at high ionic strength as they were at $25^{\circ} \mathrm{C}$. Results using Debye-Huckel activity coefficients are quite high above 1-molal $\mathrm{NaCl}$ content; 'one result, 7.8 $\times 10^{-4}$ molal $\mathrm{BaSO}_{4}$ solubility at 4-molal $\mathrm{NaCl}$ content, was not plotted. The results of REDEQL.EPAK are also in good agreement up to 1-molal $\mathrm{NaCl}$ content, but are quite low at higher ionic strengths. The reasons for this are the same as those noted for the $25^{\circ} \mathrm{C}$ results.

\section{G. Test Case 7 Results}

Figure 17 shows a plot of $\mathrm{CaSO}_{4}$ solubility as a function of total $\mathrm{NaCl}$ content of the solution at $25^{\circ} \mathrm{C}$ for Test Case 7 . The solid line is the same curve as is drawn through the experimental data at $25^{\circ} \mathrm{C}$ in Fig. 7. Figures 18 and 19 show similar plots for 100 and $250^{\circ} \mathrm{C}$ data.

At $25^{\circ} \mathrm{C}$ (Fig. 17), the results from GEOCHEM, WATEQF, and REDEQL.EPAK are in reasonable agreement with the experimental curve up to $0.5-$ molal $\mathrm{NaCl}$ content. Above that, the results from GEOCHEM are well above the curve and the results from REDEQL.EPAK and WATEQF are below. The best agreement is for WATEQF using Debye-Huckel activity coefficients. GEOCHEM results are high at high $\mathrm{NaCl}$ content for the same reason as Test Case 1; the formation of $\mathrm{CaCl}^{+}$complex ties up a substantial amount of calcium. The results from SENECA2 are slightly high at low $\mathrm{NaCl}$ content and are well above the experimental curve at high ionic strengths. The difference is caused by a combination of formation-constant and activity-coefficient data.

At $100^{\circ} \mathrm{C}$ (Fig. 18), results from SENECA2 and WATEQF are in reasonable agreement with the experimental curve. Differences at 2-4-molal $\mathrm{NaCl}$ content result from activity-coefficient data. REDEQL.EPAK results are high at low ionic strength, and have the wrong variation with $\mathrm{NaCl}$ content from 1-4 molal. The results at low ionic strength are related to formation-constant data; the trend at high ionic strength is caused by high activity coefficients for $\mathrm{Ca}^{+2}$ and $\mathrm{SO}_{4}^{-2}$ (see Test Case 1 results). GEOCHEM was not usable at 100 or $250^{\circ} \mathrm{C}$.

At $250^{\circ} \mathrm{C}$ (Fig. 19), results from SENECA2 are in reasonable agreement at low ionic strength, but fall well below the experimental curve above 1-molal $\mathrm{NaCl}$ content. Activity-coefficient data are the main cause of this difference. The results of WATEQF are very high over the entire range of $\mathrm{NaCl}$ content. The equilibrium constant for solid $\mathrm{CaSO}_{4}$ (anhydrite) formation used by WATEQF is much greater than the value used by SENECA2; this leads to considerably higher solubility. Results from REOEQL.EPAK are so high as to be above the range of the plot except for one point at 4-molal $\mathrm{NaCl}$ content. off-scale points range from 0.06-0.1-molal $\mathrm{CaSO}_{4}$ solubility. A large equilibrium constant for the formation of solid $\mathrm{CaSO}_{4}$ is the major reason for the very high solubilities predicted by REDEQL.EPAK. 


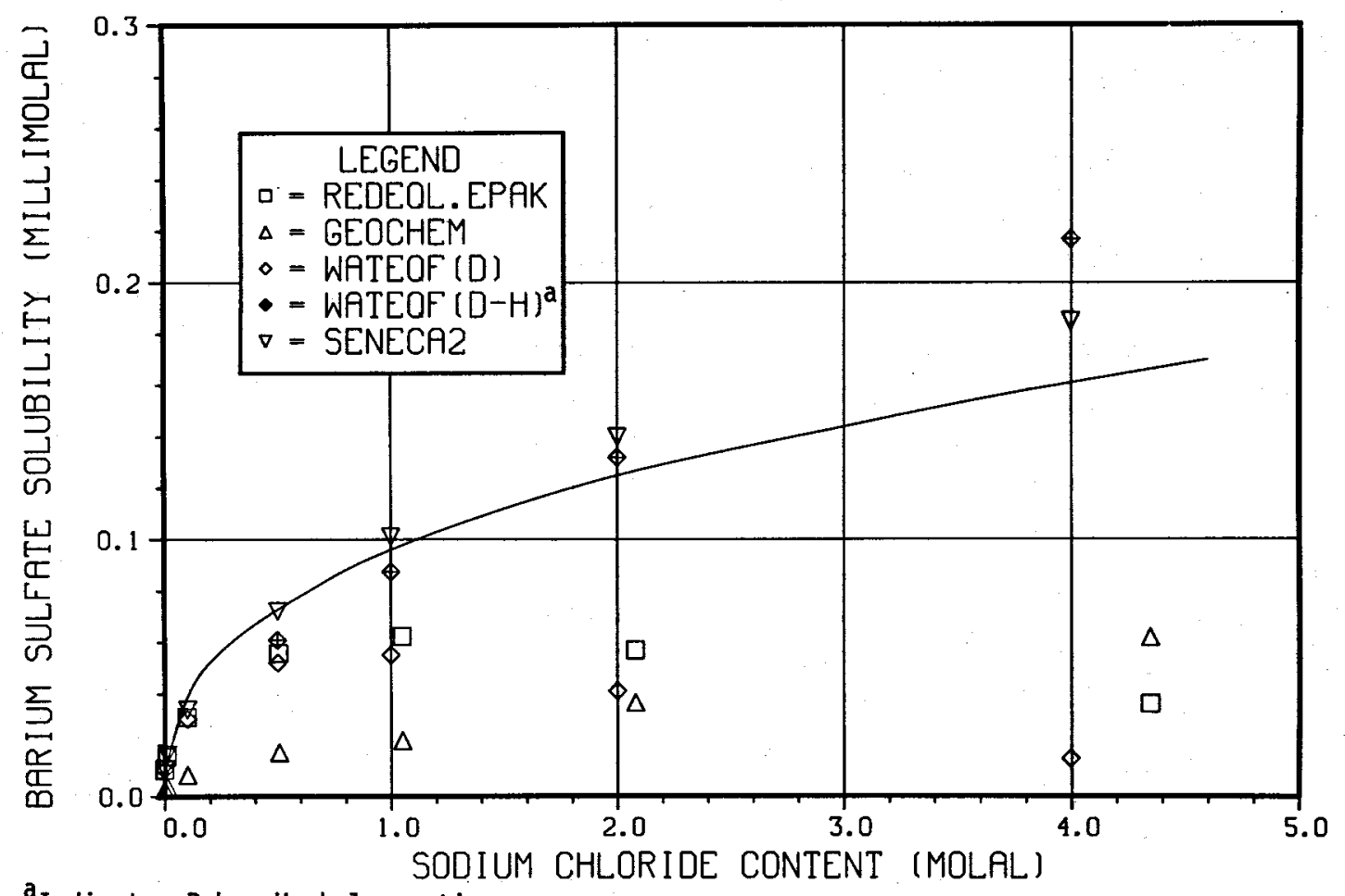

andicates Debye-Huckel equation.

Fig. 15. Results for Test Case 6 at $25^{\circ} \mathrm{C}$.

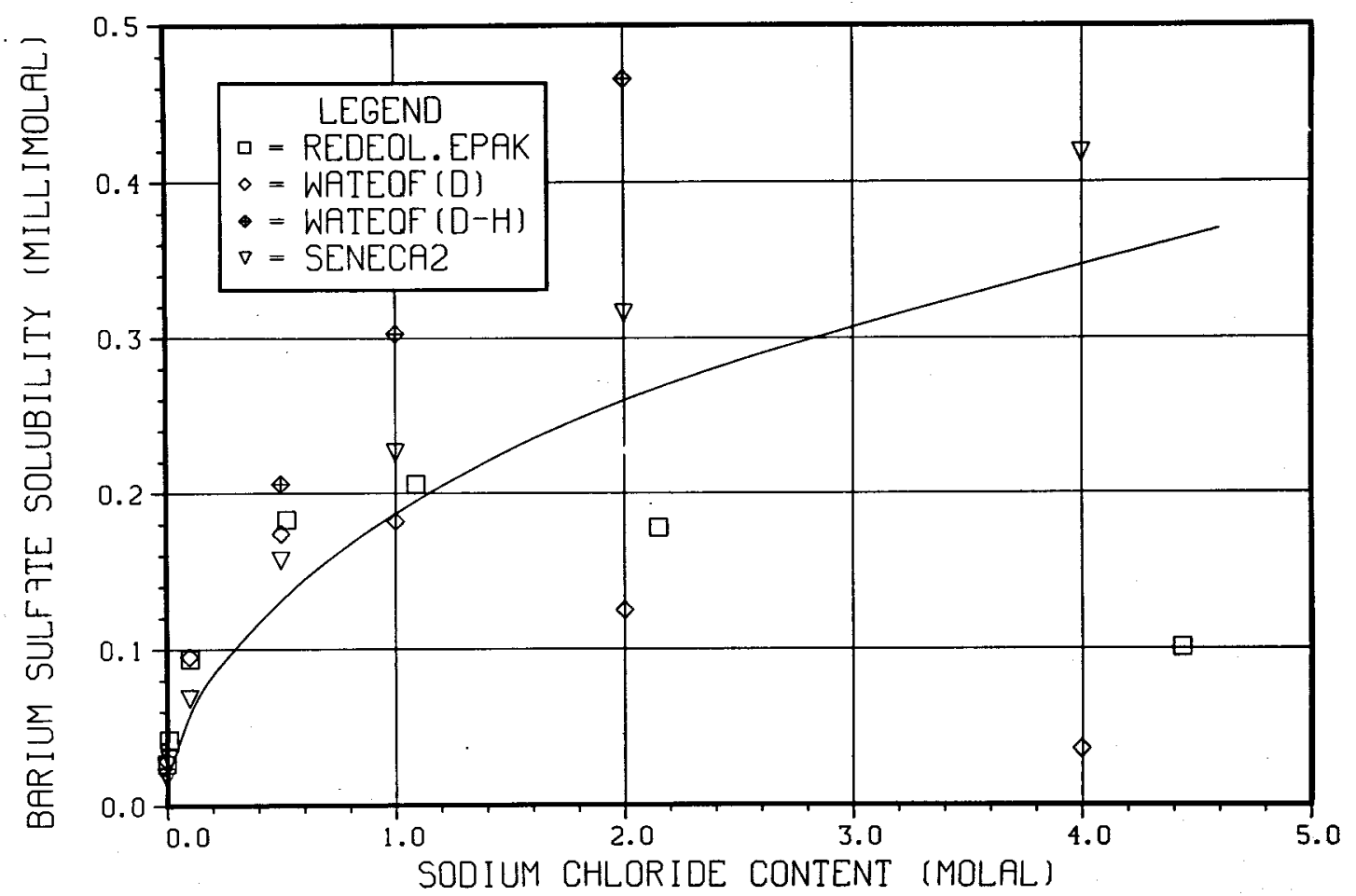

Fig. 16. Results for Test Case 6 at $95^{\circ} \mathrm{C}$. 


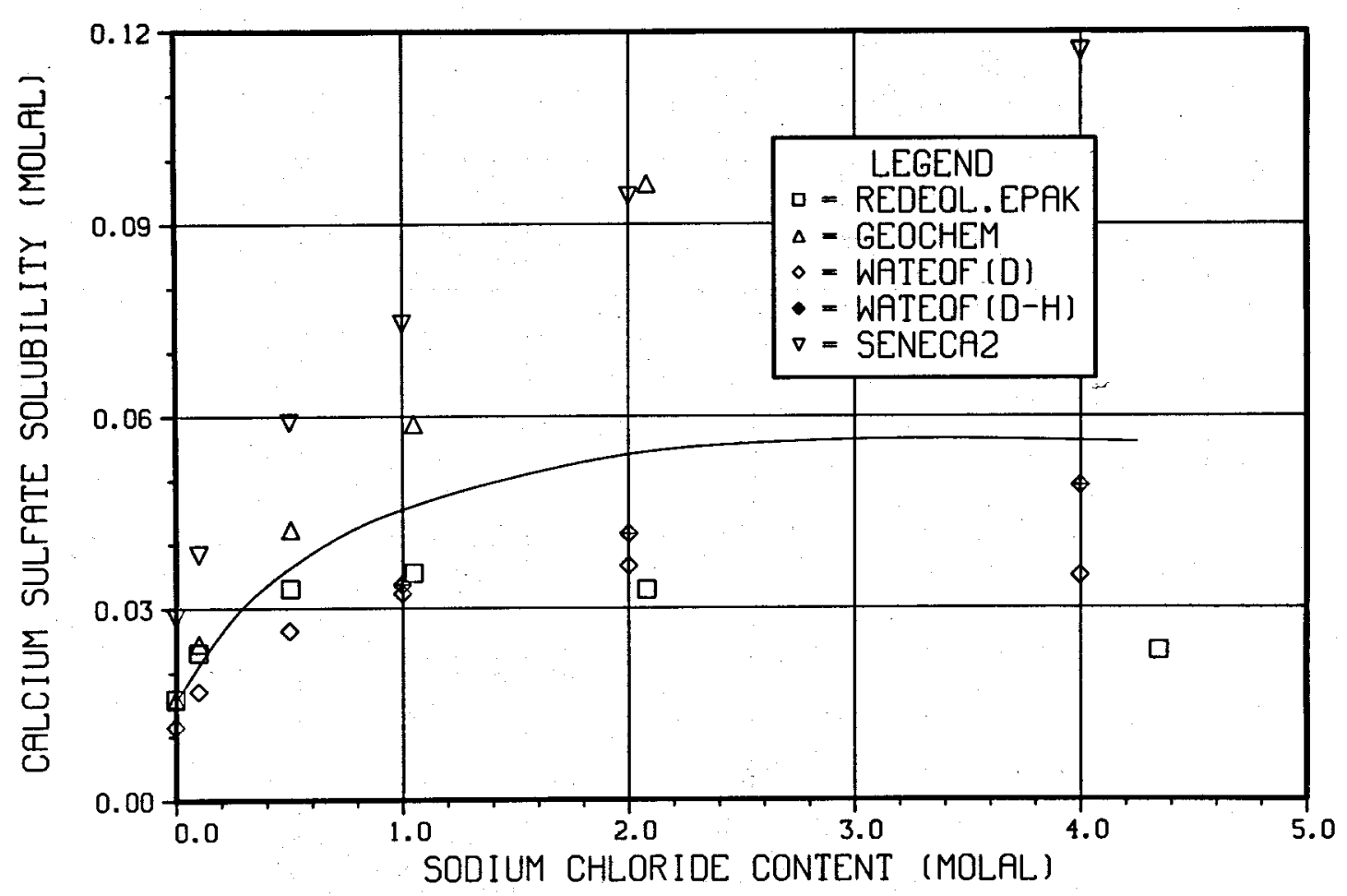

Fig. 17. Results for Test Case 7 at $25^{\circ} \mathrm{C}$.

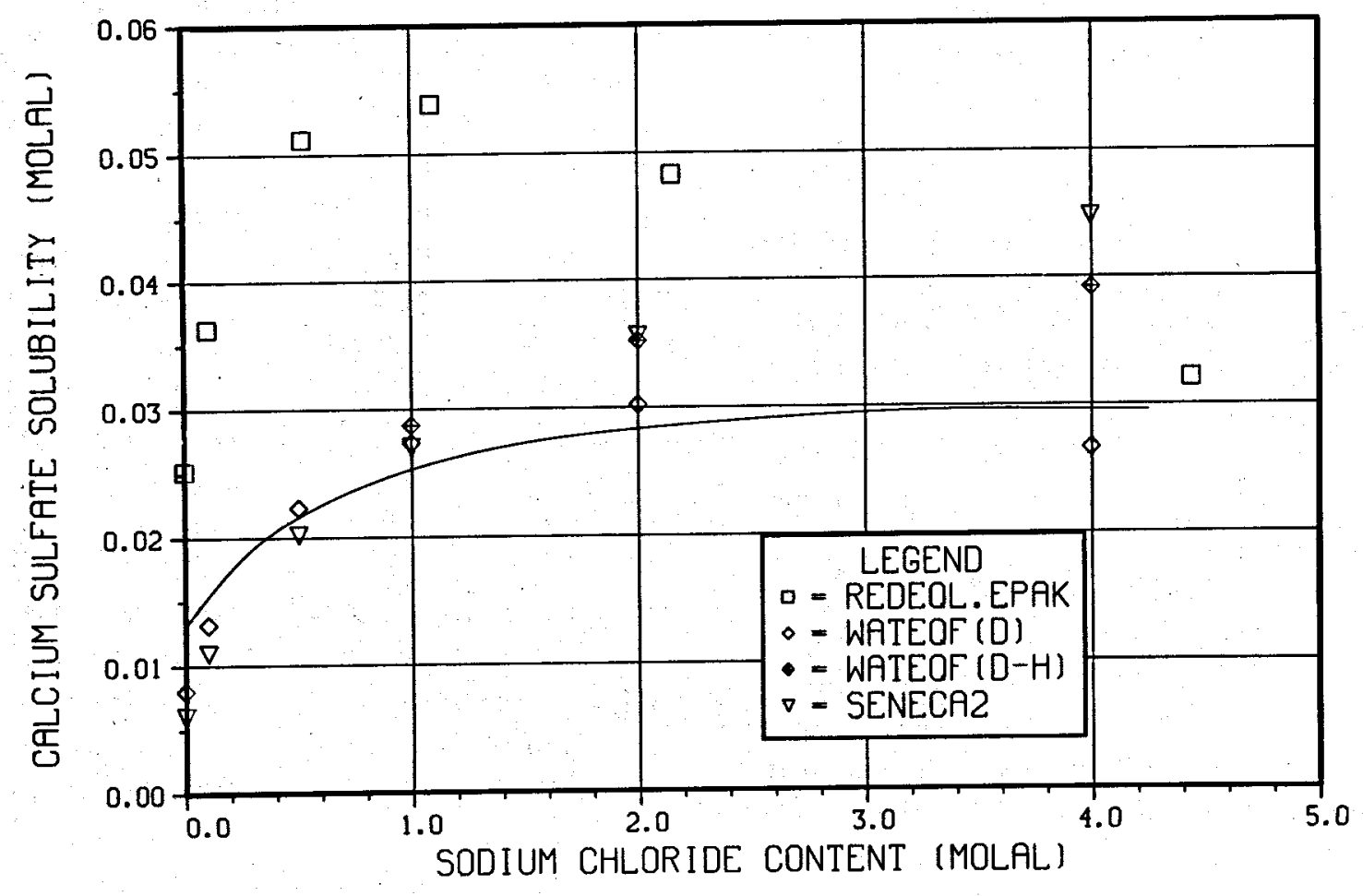

Fig. 18. Results for Test Case 7 at $100^{\circ} \mathrm{C}$. 


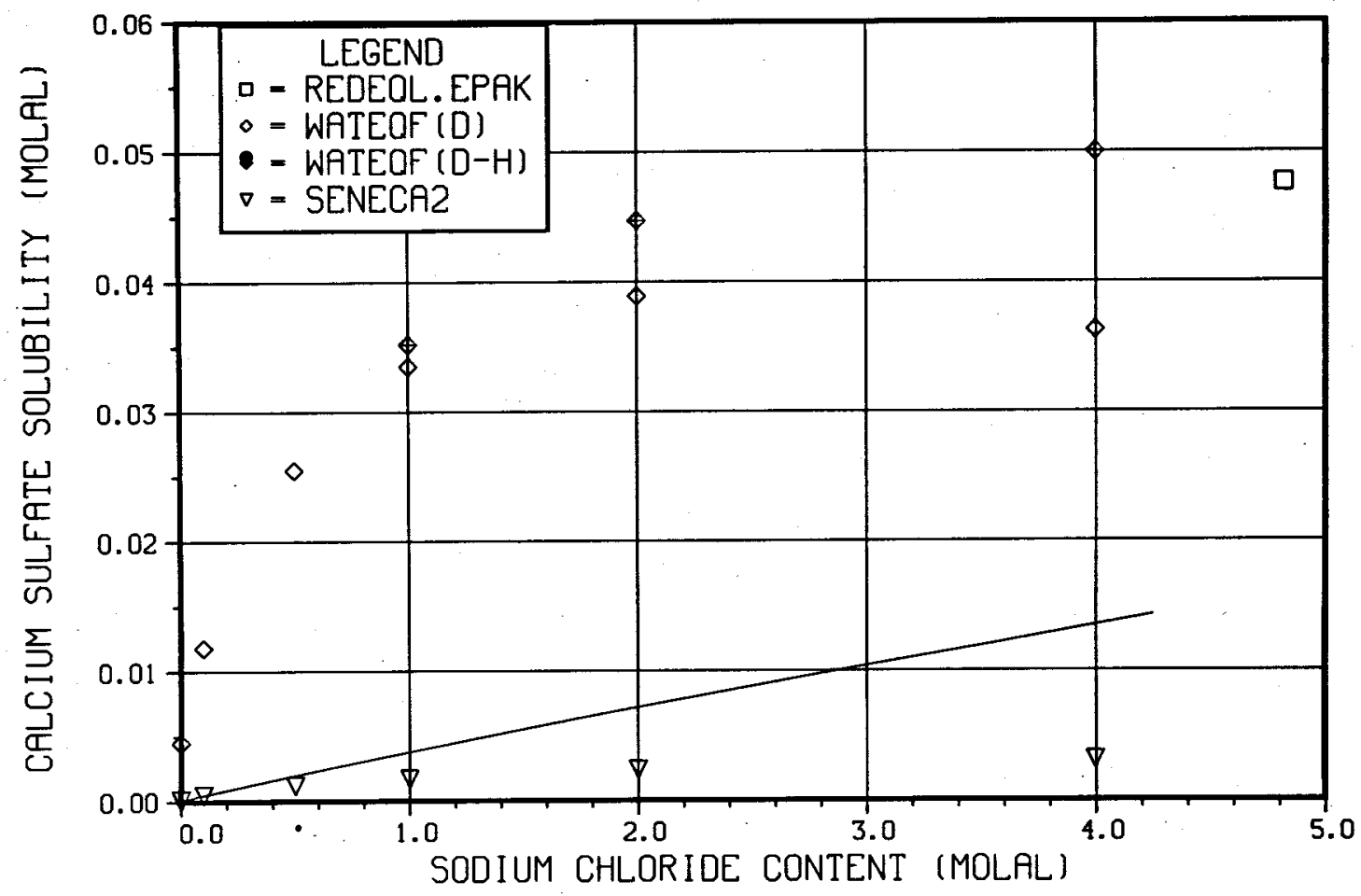

Fig. 19. Results for Test Case 7 at $250^{\circ} \mathrm{C}$.

\section{v. TIMING TESTS}

Timing tests, which compared execution times for three of the four chemical-equilibrium programs, were also performed. Test problems used for the timing tests involved solutions from which a number of possible solid phases could precipitate. WATEQF was not included in the timing tests because it does not predict actual solid phases formed (see Sec. II.C).

Table II lists total concentrations of species for three test problems. The data were assumed to be in molal units for SENECA2 and molar units for REDEQL.EPAK and GEOCHEM. No attempt was made to compare results of the three programs except for the identity of the solid phases predicted. Thus, the assumption that molal and molar units are equivalent is acceptable here. In Timing Problem 1, possible solid phases are $\mathrm{CaCO}_{3}, \mathrm{MgCO}_{3}$, $\mathrm{CaMg}\left(\mathrm{CO}_{3}\right)_{2}, \mathrm{SiO}_{2}, \quad \mathrm{ZnCO}_{3}$, and $\mathrm{PbCO}_{3}$. For Timing Problem 2, sulfide ion was added so that ZnS and PbS were also possible solids. For Timing Problem 3, the concentration of a number of ions was reduced, but possible solid phases remained the same as in Problem 2.
TABLE II TIMING TEST PROBLEMS

\begin{tabular}{|c|c|c|c|}
\hline \multirow[b]{2}{*}{ Species } & \multicolumn{3}{|c|}{ Total Concentration (molal or molar) } \\
\hline & Problem 1 & Problem 2 & Problem 3 \\
\hline $\mathrm{Na}^{+}$ & 0.500 & 0.500 & 0.500 \\
\hline $\mathrm{Cl}^{-}$ & 0.504 & 0.530 & 0.454 \\
\hline $\mathrm{Ca}^{+2}$ & 0.050 & 0.050 & 0.050 \\
\hline $\mathrm{Mg}^{+2}$ & 0.030 & 0.030 & $2 \times 10^{-3}$ \\
\hline $\mathrm{H}_{4} \mathrm{SiO}_{4}$ & 0.030 & 0.030 & $2 \times 10^{-3}$ \\
\hline $\mathrm{CO}_{3}^{-2}$ & 0.150 & 0.150 & 0.100 \\
\hline $\mathrm{H}^{+}$ & 0.240 & 0.240 & 0.150 \\
\hline $\mathrm{OH}^{-}$ & 0.100 & 0.100 & 0.100 \\
\hline $\mathrm{Zn}^{+2}$ & $1 \times 10^{-3}$ & $2 \times 10^{-2}$ & $1 \times 10^{-5}$ \\
\hline $\mathrm{Pb}^{+2}$ & $1 \times 10^{-3}$ & $2 \times 10^{-2}$ & $1 \times 10^{-5}$ \\
\hline$s^{-2}$ & - & $2.5 \times 10^{-2}$ & $1.1 \times 10^{-5}$ \\
\hline
\end{tabular}

The timing runs were made on a Los Alamos Control Data Corporation (CDC) 7600 computer operating under the LTSS time-sharing system. 30 Central processor unit (cpu) times were compared. REDEQL.EPAK and GEOCHEM were compiled as they were received except for a few small changes that were necessary for compatibility with the CDC FTN compiler. 
Table. III lists the cpu times obtained. The small differences between REDEQL.EPAK and GEOCHEM are not significant; on a time-sharing system like LTSS, small differences of this magnitude can be obtained from repeated runs of the same problem if the system load (number of users) varies. The results from these two programs are essentially the same for the three problems. SENECA2 is competitive for Timing Problem 1, but shows significantly longer cpu times for the second and third problems. SENECA2 had considerable difficulty with species present in small amounts in the third timing problem. Most of the time was spent in the first step of the calculation (see Sec. II.D.). Although this procedure minimizes the free energy of the system, it depends on the definition of a basis set or set of elemental species that must be present. ${ }^{7}$ Much of the additional time is spent changing species in the basis set during early phases of minimization.

Table IV lists the solid phases predicted for Timing Problems 1 and 2. The differences reflect a disagreement in equilibrium-constant data among the three programs. Because there are no experimental data for comparison, it is not possible to establish which solid phases are correct for these problems.

\section{vi. CONCLUSIONS}

The purpose of the work was to compare results from four chemical-equilibrium computer programs with experimental solubility data for some simple systems of geothermal interest. The test cases were rather severe on occasion, with ionic strengths up to 4 molal and temperatures up to $300^{\circ} \mathrm{C}$. None of the four programs showed consistently good agreement with experimental data. Two causes of disagreement were related to free-energy or equilibrium-constant data and to activity coefficients.

TABLE III

TIMING TEST RESULTS

\begin{tabular}{lccc} 
& \multicolumn{3}{c}{ cpu Time (s) } \\
\cline { 2 - 4 } Program & Problem 1 & $\frac{\text { Problem 2 }}{2.35}$ & $\frac{\text { Problem 3 }}{15.33}$ \\
\cline { 2 - 4 } SENECA2 & 1.63 & 2.35 & 1.12 \\
REDEQL.EPAK & 1.13 & 1.15 & 1.12 \\
GEOCHEM & 1.14 & 1.28 &
\end{tabular}

TABLE IV

SOLID PHASES PREDICTED WITH TIMING PROBLEMS

Solid Phases Predicted

\begin{tabular}{|c|c|c|c|}
\hline \multirow{2}{*}{$\begin{array}{l}\text { Timing } \\
\text { Problem } \\
\end{array}$} & \\
\hline & SENECA2 & REDEQL.EPAK & GEOCHEM \\
\hline 1 & $\begin{array}{l}\mathrm{CaCO}_{3} \\
\mathrm{ZnCO}_{3} \\
\mathrm{PbCO}_{3} \\
\mathrm{SiO}_{2} \\
\mathrm{CaMg}_{2}\left(\mathrm{CO}_{3}\right)_{2}\end{array}$ & $\begin{array}{l}\mathrm{CaCO}_{3} \\
\mathrm{ZnSiO}_{3} \\
\mathrm{PbCO}_{3} \\
\mathrm{SiO}_{2} \\
\mathrm{CaMg}_{\left(\mathrm{CO}_{3}\right)_{2}}\end{array}$ & $\begin{array}{l}\mathrm{CaCO}_{3} \\
\mathrm{ZnCO}_{3} \\
\mathrm{PbCO}_{3} \\
\mathrm{SiO}_{2}\end{array}$ \\
\hline 2 & $\begin{array}{l}\mathrm{CaCO}_{3} \\
\mathrm{ZnS} \\
\mathrm{PbS} \\
\mathrm{PbCO}_{3} \\
\mathrm{SiO}_{2} \\
\mathrm{CaMg}_{2}\left(\mathrm{CO}_{3}\right)_{2}\end{array}$ & $\begin{array}{l}\mathrm{ZnS} \\
\mathrm{ZnSiO} \\
\mathrm{PbS}_{3} \\
\mathrm{SiO}_{2} \\
\mathrm{CaMg}\left(\mathrm{CO}_{3}\right)_{2}\end{array}$ & $\begin{array}{l}\mathrm{CaCO}_{3} \\
\mathrm{ZnS} \\
\mathrm{ZnCO}_{3} \\
\mathrm{PbS} \\
\mathrm{SiO}_{2}\end{array}$ \\
\hline
\end{tabular}

All four programs give similar activity coefficients at ionic strengths in the 0-1-molal range. At higher ionic strengths, the Davies equation and its variants gave activity coefficients that were too large. Thus, REDEQL.EPAK and WATEQF (using the Davies equation) predict solubilities that are too low at high ionic strengths. The SENECA2 activity coefficients appear to yield more reasonable results at high ionic strengths. As an example of some of the differences observed, Table $V$ lists calculated activity coefficients for three species involved in the solubility reactions:

TABLE $V$

ACTIVITY COEFFICIENTS AT $25^{\circ} \mathrm{C}$

\begin{tabular}{|c|c|c|c|c|}
\hline & \multicolumn{4}{|c|}{$\begin{array}{l}\text { Activity Coefficient } \\
\text { at Ionic Strength }\end{array}$} \\
\hline & 0.1 & 0.5 & 2.0 & 4.0 \\
\hline \multicolumn{5}{|c|}{$a^{+}$} \\
\hline $\begin{array}{l}\text { REDEQL.EPAK } \\
\text { GEOCHEM } \\
\text { WATEQF }(D)^{\mathrm{a}} \\
\text { WATEQF (D-H) } \\
\text { SENECA2 }\end{array}$ & $\begin{array}{l}0.772 \\
0.780 \\
0.782 \\
0.782 \\
0.776\end{array}$ & $\begin{array}{l}0.691 \\
0.680 \\
0.708 \\
0.708 \\
0.681\end{array}$ & $\begin{array}{l}0.804 \\
0.725 \\
0.789 \\
0.789 \\
0.671\end{array}$ & $\begin{array}{l}1.169 \\
0.820 \\
1.043 \\
1.043 \\
0.752\end{array}$ \\
\hline \multicolumn{5}{|l|}{$a^{+2}$} \\
\hline $\begin{array}{l}\text { REDEQL.EPAK } \\
\text { GEOCHEM } \\
\text { WATEQF }(D)^{\mathrm{a}} \\
\text { WATEQF }(D-H)^{\mathrm{a}} \\
\text { SENECA2 }\end{array}$ & $\begin{array}{l}0.356 \\
0.371 \\
0.390 \\
0.390 \\
0.404\end{array}$ & $\begin{array}{l}0.229 \\
0.224 \\
0.260 \\
0.260 \\
0.262\end{array}$ & $\begin{array}{l}0.419 \\
0.208 \\
0.289 \\
0.289 \\
0.208\end{array}$ & $\begin{array}{l}1.868 \\
0.207 \\
0.509 \\
0.509 \\
0.215\end{array}$ \\
\hline \multicolumn{5}{|l|}{+2} \\
\hline $\begin{array}{l}\text { REDEQL.EPAK } \\
\text { GEOCHEM } \\
\text { WATEQF }(D)^{\mathrm{a}} \\
\text { WATEQF }(D-H)^{\mathrm{a}} \\
\text { SENECA2 }\end{array}$ & $\begin{array}{l}0.356 \\
0.371 \\
0.372 \\
0.376 \\
0.380\end{array}$ & $\begin{array}{l}0.229 \\
0.224 \\
0.288 \\
0.214 \\
0.225\end{array}$ & $\begin{array}{l}0.419 \\
0.208 \\
1.069 \\
0.135 \\
0.163\end{array}$ & $\begin{array}{c}1.868 \\
0.207 \\
12.3 \\
0.111 \\
0.161\end{array}$ \\
\hline
\end{tabular}

$a_{D}$ indicates Davies equation and $\mathrm{D}-\mathrm{H}$ indicates Debye-Huckel equation. 
$\mathrm{Na}^{+}, \mathrm{Ca}^{+2}$, and $\mathrm{Ba}^{+2}$. The large differences at high ionic strengths are apparent.

Inaccurate free-energy or equilibriumconstant data were a major cause of differences between calculated results and experimental data. Data for the solubility reaction itself or for formation of complexes with common ions could be at fault. GEOCHEM provided examples of both situations; a large value for the formation constant of solid $\mathrm{BaSO}_{4}$ led to low solubilities in Test Case 6 , and a large value for the formation constant of $\mathrm{CaCl}^{+}$led to high solubilities in Test Cases 1 and 7 . The other programs provided similar examples, particularly at high temperatures.

One of the four programs tested, WATEQF, is clearly not suitable for modeling precipitation from geothermal brines because it does not calculate the amounts of solid phases that are formed. Also, the necessity of specifying the $\mathrm{pH}$ of the solution complicates its use if $\mathrm{pH}$ is unknown. GEOCHEM and REDEQL.EPAK are very similar programs as far as the tests conducted here are concerned. Although REDEQL.EPAK has the capability of calculation at temperatures other than $25^{\circ} \mathrm{C}$, only a small percentage of species in the data base have the needed data available. Both programs showed good results in the timing tests. SENECA2 generally showed good results in comparisons with experimental data. The data base for SENECA2 is much smaller than that in the other three programs, but it emphasizes reactions of geothermal interest. SENECA2 might require significant modifications in the calculation procedure to improve its performance in the timing tests.

The overall conclusion of this work is that currently available chemical-equilibrium computer programs can give reasonable results when used for modeling precipitation from geothermal brines. However, considerable care must be taken to check free-energy data and activity coefficients because significant errors can be caused by inaccuracies in either type of data. If chemical modeling of geothermal brines is to become an accurate science, the two greatest needs are accurate free-energy data and an accurate method of calculating activity coefficients at high ionic strength.

\section{ACKNOWLEDGMENTS}

The author would like to acknowledge the support and help of Dr. Roy C. Feber of Los Alamos National Laboratory in this work. He would also like to thank the authors of REDEQL.EPAK, GEOCHEM, and WATEQF for making their programs available to Los Alamos. This work was supported by the US Department of Energy, Division of Geothermal Energy.

\section{REFERENCES}

1. R. C. Feber, Ed., "Proceedings of Workshop on Scale Control in Geothermal Energy Extraction Systems," Los Alamos. Scientific Laboratory report LA-7664-C (April 1979).

2. F. van Zeggeren and S. H. Storey, The Computation of Chemical Equilibria TCambridge University Press, London, 1970).

3. J. N. Butler, Ionic Equilibria, A Mathematical Approach (Addison-Wesley Publishing Co., Reading, Massachusetts, 1964), pp. 428-439.

4. S. E. Ingle, M. D. Schuldt, and D. W. Schults, "A User's Guide for REDEQL.EPAK", Environmental Protection Agency report EPA-600/3-78-024 (February 1978);. S. E. Ingle, J. A. Keniston, and D.W. Schults, "REDEQL.EPAK, Aqueous Chemical Equilibrium Program," Corvallis Environmental Research Laboratory, Corvallis, Oregon (1979).

5. G. Sposito and S. V. Mattigod, "GEOCHEM: A Computer Program for the Calculation of Chemical Equilibria in Soil Solutions and Other Natural Water Systems," Department of Soil and Environmental Sciences, University of California, Riverside, California (1979).

6. L. N. Plummer, B. F. Jones, and A. H. Truesdell, "WATEQF: A FORTRAN IV Version of WATEQ, A Computer Program for Calculating Chemical Equilibrium of Natural Waters, Users Guide," US Geological Survey report USGS-WRI-76-13 (September 1976).

7. Y. H. Ma and C. W. Shipman, "On the Computation of Complex Equilibria," AIChE Journal 18, 299-304 (1972).

8. C. W. Davies, "The Extent of Dissociation of Salts in Water, Part VIII, An Equation for the Mean Ionic Activity Coefficient of an Electrolyte in Water, and a Revision of the Dissociation Constants of Some Sulphates," Jour. Chem. Soc., London, Part II, 2093-2098 (1938).

9. A. H. Truesdell and B. F. Jones, "WATEQ, A Computer Program for Calculating Chemical Equilibria of Natural Waters," Jour. Res. US Geol. Survey 2, 233-248 (1974). 
10. L. M. Naphtali, "Computing Complex Chemical Equilibria by Minimizing Free Energy," Proc. First Conf. Kinetics, Equilibria and Performance of High Temperature Systems, Los Angeles, California, November 2-5, 1959 (Butterworths, London, 1960), pp. 181-183.

11. H. C. Helgeson, "Thermodynamics of Hydrothermal Systems at Elevated Temperatures and Pressures," Amer. Jour. Science 267, 729-804 (1969).

12. H. C. Helgeson, J. M. Delany, H. W. Nesbitt, and D. K. Bird, "Summary and Critique of the Thermodynamic Properties of Rock-Forming Minerals," Amer. Jour. Science 278-A, 1-220 (1978).

13. H. C. Helgeson, T. H. Brown, A. Nigrini, and T. A. Jones, "Calculation of Mass Transfer in Geochemical Processes Involving Aqueous Solutions," Geochimica et Cosmochimica Acta 34, 569-592 (1970).

14. F. K. Cameron, J. M. Bell, and W. O. Robinson, "The Solubility of Certain Salts Present in Alkali Soils," Jour. Phys. Chem., II, 396-420 (1907).

15. G. L. Frear and J. Johnstoin, "The Solubility of Calcium Carbonate (Calcite) in Certain Aqueous Solutions at $25^{\circ} \mathrm{C}$," Jour. Amer. Chem. Soc. 51, 2082-2093 (1929).

16. E. B. Shternina and E. V. Frolona, "The System $\mathrm{CaCO}_{3}-\mathrm{CaSO}_{4}-\mathrm{NaCl}-\mathrm{H}_{2} \mathrm{O}$ at $25^{\circ} \mathrm{C}$," Compt. Rend. Acad. Sci. URSS, 47 (1945) in W. F. Linke, Solubilities, Inorganic and Metal-Organic Compounds (Amer. Chem. Soc., Washington, DC, 1958), p. 544 .

17. W. F. Linke, Solubilities, Inorganic and Metal-Organic compounds (Amer. Chem. Soc., Washington, DC, 1958), data of Yanat'ena, $p$. 545.

18. A. J. Ellis, "The Solubility of Calcite in Sodium Chloride Solutions at High Temperatures," Amer. Jour. Science 261, 259-267 (1963).
19. J. P. Miller, "A Portion of the System Calcium Carbonate-Carbon Dioxide-Water, with Geological Implications," Amer. Jour. Science 250, 161-203 (1952).

20. G. B. Alexander, W. M. Heston, and R. K. Iler, "The Solubility of Amorphous Silica in Water," Jour. Phys. Chem. 58, 453-455 (1954).

21. G. C. Kennedy, "A Portion of the System Silica-Water," Economic Geology 45, 629-653 (1950).

22. R. 0. Fournier and J. J. Rowe, "The Solubility of Amorphous Silica in Water at High Temperatures and High Pressures," Amer. Mineralogist 62, $1052-1056$ (1977).

23. V. Lenher and H. B. Merrill, "The Solubility of Silica," Jour. Amer. Chem. Soc., 39, 2630-2638 (1917).

24. c. C. Templeton, "Solubility of Barium Sulfate in Sodium Chloride Solutions from $25^{\circ}$ to $95^{\circ} \mathrm{C}, "$ Jour. Chem. Eng. Data 5, 514-516 (1960).

25. C. W. Blount, "Barite Solubilities and Thermodynamic Quantities up to $300^{\circ} \mathrm{C}$ and 1400 Bars," Amer. Mineralogist 62, 942-957 (1977).

26. W. L. Marshall and R. Slusher, "Thermodynamics of Calcium Sulfate Dihydrate in Aqueous Sodium Chloride Solutions, $0-110^{\circ}$," Jour. Phys. Chem. 70, 4015-4027 (1966).

27. C. C. Templeton and J. C. Rodgers, "Solubility of Anhydrite in Several Aqueous Salt Solutions Between $250^{\circ}$ and $325^{\circ} \mathrm{C}$," Jour. Chem. Eng. Data 12, 536-547 (1967).

28. J. Block and 0. B. Waters, Jr., "The $\mathrm{CaSO}_{4-}$ $\mathrm{Na}_{2} \mathrm{SO}_{4}-\mathrm{NaC}_{1}-\mathrm{H}_{2} \mathrm{O}$ System at $25^{\circ}$ to $100^{\circ} \mathrm{C}$," Jour. Chem. Eng. Data 13, 336-344 (1968).

29. J. L. Haas, Jr., "Preliminary Steam Tables for NaCl Solutions, " US Geological Survey report 75-674 (Ju7y 1975).

30. "LTSS User's Guide," Los Alamos Scientific Laboratory report LA-5525-M, Vo1. 6 (revised February 1980). 


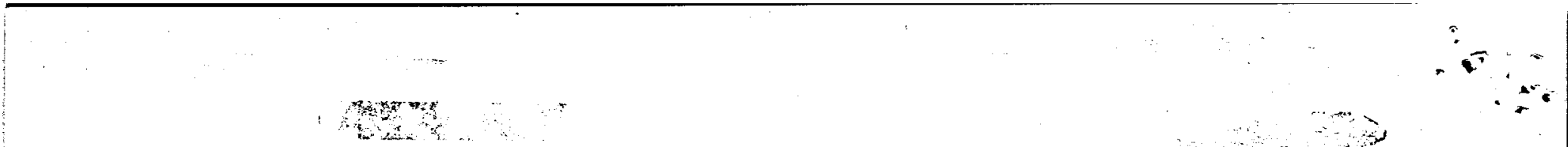

$\mathrm{s}_{\mathrm{L}} \mathrm{s}$ 